\title{
Global ionosphere-polar wind system during changing magnetic activity
}

\author{
R. W. Schunk and J. J. Sojka \\ Center for Atmospheric and Space Sciences, Utah State University, Logan
}

\begin{abstract}
A time-dependent, three-dimensional, multi-ion model of the global ionosphere-polar wind system was used to study the system's response to an idealized geomagnetic storm for different seasonal and solar cycle conditions. The model covered the altitude range from 90 to 9000 $\mathrm{km}$ for latitudes greater than $50^{\circ}$ magnetic in the northern hemisphere. The geomagnetic storm contained a 1-hour growth phase, a 1-hour main phase, and a 4-hour decay phase. Four storm simulations were conducted, corresponding to winter and summer solstices at both solar maximum and minimum. The simulations indicated the following: (1) $\mathrm{O}^{+}$upflows typically occur in the cusp and auroral zone at all local times, and downflows occur in the polar cap. However, during increasing magnetic activity, $\mathrm{O}^{+}$upflows can occur in the polar cap, (2) The $\mathrm{O}^{+}$upflows are typically the strongest where both $T_{e}$ and $T_{i}$ are elevated, which generally occurs in the cusp at the location of the dayside convection throat, (3) The upward $\mathrm{H}^{+}$and $\mathrm{O}^{+}$velocities increase with $T_{e}$, which results in both seasonal and day-night asymmetries in the ion velocities, (4) During "increasing" magnetic activity, $\mathrm{O}^{+}$is the dominant ion at all altitudes throughout the polar region, (5) For solar minimum winter, there is an $\mathbf{H}^{+}$"blowout" throughout the polar region shortly after the storm commences (negative storm effect), and then the $\mathrm{H}^{+}$density slowly recovers. The $\mathrm{O}^{+}$ behavior is opposite to this. There is an increase in the $\mathrm{O}^{+}$density above $1000 \mathrm{~km}$ during the storm's peak (positive storm effect), and then it decreases as the storm subsides, and (6) For solar maximum summer, the $\mathrm{O}^{+}$and $\mathrm{H}^{+}$temporal morphologies are in phase; but the ion density variations at high altitudes are opposite to those at low altitudes. During the storm's peak, the $\mathrm{H}^{+}$ and $\mathrm{O}^{+}$densities increase at high altitudes (positive storm effect) and decrease at low altitudes (negative storm effect).
\end{abstract}

\section{Introduction}

At high latitudes, the Earth's geomagnetic field is stretched into a long comet-like tail on the nightside that extends past the Moon's orbit. The magnetic field lines that form the tail originate in the polar region, and since the pressure in the ionosphere is much greater than that in the distant tail, it was suggested that a continual escape of thermal plasma $\left(\mathrm{H}^{+}\right.$and $\mathrm{He}^{+}$) should occur along these "open" field lines [Bauer, 1966; Dessler and Michel, 1966]. These early suggestions of light ion outflow were based on a thermal evaporation process, in which the light ions escape the topside ionosphere with speeds close to their thermal velocities. However, it was subsequently argued that the outflow should be supersonic, and it was called the "polar wind" in analogy to the solar wind [Axford, 1968; Banks and Holzer, 1968, 1969]. Measurements later confirmed the supersonic nature of the outflow by both direct and indirect means [Hoffiman' and Dodson, 1980; Nagai et al., 1984; Gurgiolo and Burch, 1985; Persoon et al., 1983].

After 30 years of intensive study, it is now well known that the "classical" polar wind is an ambipolar outflow of thermal plasma. As the plasma flows up and out of the topside ionosphere along diverging geomagnetic flux tubes, it undergoes four major transitions, including a transition from chemical to diffusion dominance, a transition from subsonic to

Copyright 1997 by the American Geophysical Union.

Paper number 97JA00292.

0148-0227/97/97JA-00292\$09.00 supersonic flow, a transition from collision-dominated to collisionless regimes, and a transition from a heavy to a light ion. At times, however, $\mathrm{O}^{+}$can remain the dominant ion to very high altitudes in the polar cap. Another important aspect of the flow concerns its horizontal motion. Because of magnetospheric electric fields, the high-latitude ionospherepolar wind system is in a continual state of motion, convecting into and out of the cusp, polar cap, nocturnal oval, nighttime trough, and sunlight. This horizontal motion is significant because the time it takes the polar wind to flow up and out of the topside ionosphere is comparable to the transit time across the polar cap, and hence the "local" conditions are constantly changing.

Because of the complicated nature of the flow, numerous mathematical approaches have been used over the years to model the classical polar wind, including hydrodynamic, hydromagnetic, generalized transport, kinetic, semikinetic, and macroscopic particle-in-cell models. Also, numerous studies have been conducted of the "nonclassical" polar wind, which may contain; for example, ion beams or hot electrons. Polar wind studies have been conducted of its supersonic nature [Banks and Holzer, 1968, 1969; Raitt et al., 1975; Schunk et al., 1978], its anisotropic thermal structure [Holzer et al., 1971; Lemaire, 1972a; Lemaire and Scherer, 1970, 1973; Schunk and Watkins, 1981, 1982; Ganguli et al., 1987; Demars and Schunk, 1989], its evolution through the collision-dominated to collisionless transition region [Barakat et al., 1990; Wilson, 1992; Barghouthi et al., 1993], its inherent stability as well as its stability in the presence of bulk heating, $\mathrm{H}^{+}$beams, and $\mathrm{H}^{+}$- 
$\mathrm{O}^{+}$counterstreaming [Barakat and Schunk, 1987, 1989; Bergmann et al., 1988; Chen and Ashour-Abdalla, 1990], and the maximum ion escape fluxes that are possible for different seasonal and solar cycle conditions [Barakat et al., 1987; Cannata and Gombosi, 1989].

Studies have also been conducted of the extent to which various processes can affect the polar wind, including charge exchange [Moore, 1980; Barakat and Schunk, 1984b], photoelectrons [Lemaire, 1972b; Yasseen et al., 1989; Tam et al., 1995], elevated thermal electron temperatures [Barakat and Schunk, 1983; Wilson et al., 1990; Blelly and Alcaydé, 1994; Blelly et al., 1996], elevated thermal ion temperatures at low, middle, and high altitudes [Raitt et al., 1977; Gombosi et al., 1985; Gombosi and Killeen, 1987; Schunk and Sojka, 1989; Loranc and St.-Maurice, 1994; Wilson, 1994], imposed transverse ion heating [ $\mathrm{Li}$ et al., 1988], hot electrons and ions of magnetospheric origin [Lemaire and Scherer, 1978; Barakat and Schunk, 1984a], centrifugal acceleration [Cladis, 1986; Swift, 1990; Horwitz et al., 1994; Demars et al., 1996], waveparticle interactions in the polar cap [Chen and Ashour-Abdalla, 1990; Barakat and Barghouthi, 1994], and field-aligned auroral currents [Mitchell and Palmadesso, 1983; Ganguli and Palmadesso, 1987, 1988; Gombosi and Nagy, 1989]. In addition, studies have been conducted to determine polar wind propagation characteristics by imposing artificial density enhancements and depletions at various altitudes [Sing h and Schunk, 1985; Gombosi and Schunk, 1988; Ho et al., 1993; Blelly and Schunk, 1993]. Finally, many studies have been conducted in which different mathematical approaches were compared for the same polar wind scenario [Palmadesso et al., 1988; Demars and Schunk, 1992].

The purpose of the above discussion was simply to show the myriad of processes that could be operating in the "real" polar wind and the extensive work done to date. Further details concerning these processes and a more complete reference list can be found in reviews by Schunk [1988b], which covers work done prior to the mid-eighties, and by Ganguli [1996], which primarily focuses on work done after the mid-1980s. The large number of possible processes must be kept in mind when results from relatively simple simulations, containing only one or two of the processes, are compared to satellite measurements.

Prior to the mid-1980s, nearly all of the theoretical studies were for "steady state" conditions, while after this time most of the work focused on the temporal characteristics of the polar wind. Except for the three-dimensional simulations by Schunk and Sojka [1989] and Ganguli [1993, 1994], all of the timedependent polar wind simulations conducted to date were based on "one-dimensional" models applied to single, "fixed" locations, with the temporal variations driven by either assumed or measured energy inputs. The three-dimensional model recently developed by Ganguli [1993, 1994] selfconsistently takes into account cross-field transport due to plasma instabilities, but it has a restrictive spatial domain in the direction perpendicular to B. On the other hand, the threedimensional model we developed is global, but it does not selfconsistently include the effects of plasma instabilities.

Our three-dimensional model is a time-dependent multi-ion model of the global ionosphere-polar wind system. The model covers latitudes greater than $50^{\circ}$ magnetic and altitudes from 90 to $9000 \mathrm{~km}$. In the first application of the model [Schunk and Sojka, 1989], we studied the temporal evolution of the global polar wind in response to changing magnetospheric conditions. From this study we found that (1) Plasma pressure changes in the ionosphere due to $T_{e}, T_{i}$, or $\mathrm{N}_{\mathrm{e}}$ variations produce disturbances in the polar wind. In particular, the horizontal motion of the convecting plasma through the auroral oval and high electric field regions produces transient large-scale ion upflows and downflows, (2) The density structure in the polar wind is more complicated than in the ionosphere because the vertical propagation speeds change as the plasma convects into different high-latitude regions, (3) During increasing magnetic activity, there is an overall increase in the polar wind outflow from the ionosphere, while the reverse is true for declining magnetic activity. However, localized ionospheric depletions can occur during increasing magnetic activity, and in these regions the polar wind outflow rate is reduced, (4) There are significant time delays with respect to when disturbances in the ionosphere create disturbances at high altitudes in the polar wind.

The global simulation discussed by Schunk and Sojka [1989] was for only one set of geophysical conditions and the focus was mainly on elucidating ionosphere-polar wind coupling processes. In this investigation, we consider four geophysical cases, including summer and winter solstices at both solar maximum and minimum. Hence we are able to show how the stormtime response of the ionosphere-polar wind system changes as the seasonal and solar cycle conditions change. Also, much more information is provided on the global response as a function of altitude and time, and spatially integrated ion fluxes across selected altitudes are presented as a function of time throughout the storm period.

\section{Coupled Ionosphere-Polar Wind Model}

Our three-dimensional time-dependent model of the polar wind consists of a low-altitude ionosphere-atmosphere model and a high-altitude hydrodynamic model. The two models and their coupling are briefly described in the following subsections.

\subsection{Low-Altitude Ionospheric Model}

The low-altitude model is a time-dependent, threedimensional, multi-ion model of the global ionosphere that covers the altitude range from 90 to $800 \mathrm{~km}$. With this model, the density distributions of six ion species and the electron and ion temperatures are obtained from a numerical solution of the appropriate continuity, momentum, and energy equations. At mid latitudes and high latitudes, the equations are solved as a function of altitude for an inclined magnetic field. The threedimensional nature of the model is obtained by following a large number of plasma flux tubes as they convect or corotate through a moving neutral atmosphere. The model takes account of field-aligned diffusion, cross-field electrodynamic drifts, thermospheric winds, polar wind escape, energy-dependent chemical reactions, neutral composition changes, ion production due to solar UV/EUV radiation and auroral precipitation, thermal conduction, diffusion-thermal heat flow, ion temperature anisotropies, and a host of local heating and cooling processes. The model also takes account of the displacement between the geographic and geomagnetic poles. At the end of a simulation, the model outputs global density distributions for $\mathrm{NO}^{+}, \mathrm{O}_{2}^{+}, \mathrm{N}_{2}^{+}, \mathrm{N}^{+}, \mathrm{O}^{+}, \mathrm{He}^{+}$, and electrons, global $T_{e}$ and $T_{i}$ distributions, the ion temperature anisotropy distribution, and the plasma diffusion, $\mathbf{E} \times \mathbf{B}$ drift, and windinduced velocity components [cf. Schınk and Raitt, 1980; Sojka and Schunk, 1985; Schunk, 1988a, Sojka, 1989]. 


\subsection{High-Altitude Polar Wind Model}

The high-altitude model is based on a numerical solution of the time-dependent, nonlinear, continuity and momentum equations for $\mathrm{H}^{+}, \mathrm{O}^{+}$, and electrons. The equations are solved along a diverging magnetic flux tube over the altitude range from 500 to $9000 \mathrm{~km}$. The model takes account of the nonlinear inertial terms, pressure gradients, gravity, polarization electric fields, magnetic field divergence, anisotropic ion temperatures, chemical reactions, Coulomb collisions, and ion-neutral collisions. The collision frequencies adopted are appropriate for arbitrary relative drifts and arbitrary temperature differences between the interacting species.

The behavior of the ion and electron temperatures are governed by simple equations of state. The electron temperature is assumed to be isotropic at all altitudes and, hence, only one equation of state is needed. The $\mathrm{H}^{+}$and $\mathrm{O}^{+}$temperatures, on the other hand, are anisotropic, and separate equations of state are adopted for the parallel and perpendicular temperatures of each species [cf. Schunk and Sojka, 1989].

The outputs of the model are global distributions for the $\mathrm{H}^{+}$, $\mathrm{O}^{+}$and electron densities, field-aligned velocities, and temperatures.

\subsection{Model Coupling and Numerical Details}

The low-altitude ionospheric model and the high-altitude hydrodynamic model are coupled in the manner shown schematically in Figure 1. The coupling is done for each of the convecting flux tubes of plasma. In the low-altitude domain,

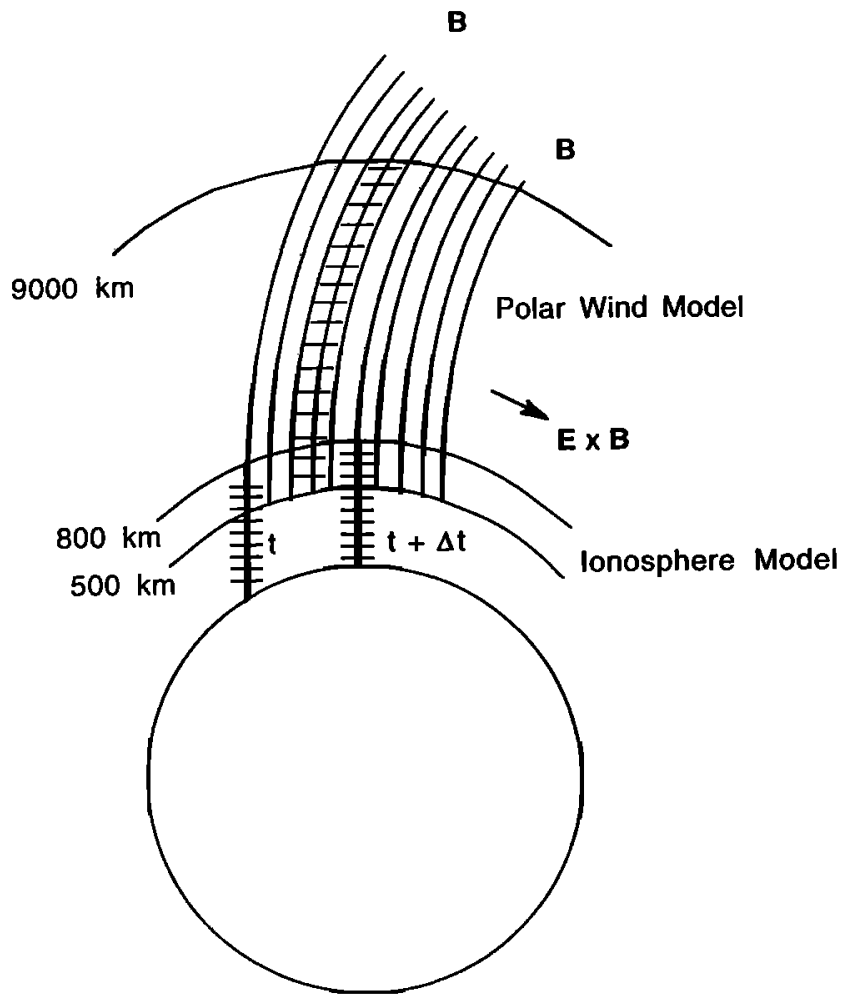

Figure 1. Schematic diagram showing the coupling of the low-altitude ionospheric model and the high-altitude polar wind model. The ionospheric model is solved over the altitude range from 90 to $800 \mathrm{~km}$ and the hydrodynamic model over the range from 500 to $9000 \mathrm{~km}$. The models are run in parallel for each convecting flux tube of plasma. The space and time steps used in the two models are different. altitude profiles of the ion and electron densities, velocities, and temperatures are obtained by solving time-dependent, second-order, diffusion, and heat conduction equations of the parabolic type. The equations are solved with a completely implicit numerical technique over the altitude range from 90 to $800 \mathrm{~km}$. A $4 \mathrm{~km}$ spatial step is used in the vertical direction and the time step typically varies from 10 to $100 \mathrm{~s}$ as the flux tube of plasma moves along a convection trajectory.

For the density boundary conditions, chemical equilibrium is assumed at $90 \mathrm{~km}$, and no escape flux is assumed for $\mathrm{NO}^{+}, \mathrm{O}_{2}{ }^{+}$, $\mathrm{N}_{2}^{+}$, and $\mathrm{N}^{+}$at $800 \mathrm{~km}$. The $\mathrm{O}^{+}$flux at $800 \mathrm{~km}$, at the beginning of a time step, is obtained from the high-altitude hydrodynamic model at the end of the previous time step. For the temperature boundary conditions, local thermal equilibrium is assumed at 90 $\mathrm{km}$, and ion and electron heat fluxes are specified at $800 \mathrm{~km}$. The ion heat fluxes are taken to be zero because of a lack of measurements. The electron heat flux at $800 \mathrm{~km}$ depends on the solar zenith angle and on the intensity of electron precipitation. It is calculated in the manner prescribed by Schunk et al. [1986].

In the high-altitude domain, profiles of the $\mathrm{H}^{+}, \mathrm{O}^{+}$, and electron densities and drift velocities are obtained by solving the time-dependent, nonlinear, hydrodynamic equations along the magnetic field. The equations, which are hyperbolic, are solved with a flux-corrected-transport (FCT) technique [cf. Boris and Book, 1976]. The equations are solved over the altitude range from 500 to $9000 \mathrm{~km}$ with a space step that varies from 10 to $45 \mathrm{~km}$ and a time step that varies from 0.1 to $0.25 \mathrm{~s}$ as the flux tube moves along a convection trajectory. The varying spatial and temporal steps and the relatively small time step are needed in order to satisfy the numerical stability criterion associated with the FCT technique. Hence there are many hydrodynamic model time steps during one ionospheric model time step.

Note that the two models overlap each other in the 500 to $800 \mathrm{~km}$ region. This overlapping is needed so that the models can provide more reliable boundary conditions to each other. For the hydrodynamic model, the $\mathrm{O}^{+}$density and velocity boundary values at $500 \mathrm{~km}$ and at the beginning of a time step are obtained from the low-altitude ionospheric model at the end of its last time step. For $\mathrm{H}^{+}$, the boundary density at $500 \mathrm{~km}$ is obtained assuming chemical equilibrium and using the $\mathrm{O}^{+}, \mathrm{O}$ and $H$ values from the low-altitude model at its last time step. The $\mathrm{H}^{+}$drift velocity at $500 \mathrm{~km}$ (in the chemical equilibrium region) is assumed to be zero. At the upper boundary $(9000 \mathrm{~km})$, the $\mathrm{O}^{+}$ and $\mathrm{H}^{+}$drift velocities are obtained via extrapolation from altitudes immediately below the boundary, but they are not allowed to be downward. With regard to the temperatures, the values obtained from the low-altitude model at its last time step at altitudes between 500 and $800 \mathrm{~km}$ are used in the hydrodynamic model. Above $800 \mathrm{~km}$, the equations of state are used [cf. Schunk and Sojka, 1989].

We did not include $\mathrm{He}^{+}$in the high-altitude hydrodynamic model for this study because this would have significantly increased the computing time.

\section{Magnetospheric-Atmospheric Inputs and Initial Conditions}

As with all geophysical models, our global ionosphere-polar wind model requires several inputs. In the high latitude region, the most important inputs are the plasma convection and particle precipitation patterns, and the thermospheric densities, 
temperatures, and winds. For time-dependent simulations, these inputs must be specified as a function of time. In this investigation, our interest is in studying the temporal variations of the global polar wind during changing magnetospheric conditions, with the emphasis on how time varying plasma convection and particle precipitation patterns affect the polar wind. In the simulations, an "idealized" geomagnetic storm is configured, and then the "global" response of the polar wind is calculated for different seasonal and solar cycle conditions. Of particular interest is how the polar wind responds at high, middle, and low altitudes to the storm and then how the response changes as the seasonal and solar cycle conditions change.

\subsection{Magnetospheric Inputs}

We do not attempt to model a specific geomagnetic storm, which can be complex. Instead, we try to capture the essential features of a storm, including the growth, main, and decay phases as well as the overall variations in the convection and precipitation patterns that are expected during the different phases. Specifically, as magnetic activity increases, it is well known that the plasma convection and auroral precipitation patterns expand, that the convection speeds increase, and that particle precipitation becomes more intense. The reverse is known to occur during decreasing magnetic activity. These are the essential storm features that we want to model.

Figure 2 shows the assumed variation of $K p$ for our idealized geomagnetic storm. Initially, $K p$ is constant and equal to 1 . At $0400 \mathrm{UT}, K p$ increases exponentially over a 1 -hour period from 1 to 6 . This value is maintained for a 1-hour period, and then $K p$ decreases exponentially to 1 over a 4-hour period. After this time, $K p$ is held fixed at 1 . Changing magnetic conditions occur only over a 6-hour period, from 0400 to 1000 UT. The simulation is then continued for an additional 6 hours in order to allow sufficient time for the polar wind to relax back to a quiet time situation.

The dependence of the convection pattern on $K p$ is still not well known. However, in our study, $K p$ is only used as a guide in producing a time-varying convection pattern. The convection pattern adopted for the study is the HeppnerMaynard "BC" pattern, which is appropriate for southward

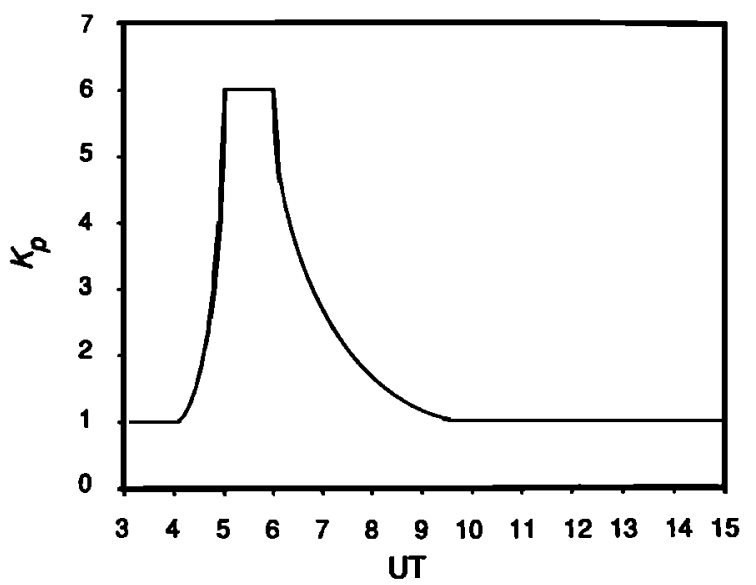

Figure 2. Variation of $K p$ with time for an idealized geomagnetic storm. Prior to the storm $K p=1$. The activity commences at 0400 UT. The increase in activity is exponential and lasts for 1 hour, $K p$ then remains constant for 1 hour, and this is followed by a 4-hour exponential decay in activity. interplanetary magnetic field (IMF) and $B_{y}>0$ in the noithern hemisphere [Heppner and Maynard, 1987]. This is an asymmetric, two-cell convection pattern with enhanced flow in the dawn cell. During changing magnetic activity, the size of the pattern and the cross polar cap potential $(\Phi)$ are varied continuously, following the $K p$ variation shown in Figure 2 . The simple linear relationship proposed by Heppner [1973] is used to relate $K p$ to $\Phi ; \Phi=20+13 K p(\mathrm{keV})$. For auroral electron precipitation, the Hardy et al. [1985] model is used. As with the convection electric field pattern, the precipitation pattern is varied continuously according to the $K p$ variation shown in Figure 2. During changing magnetic activity, both the size of the oval and the intensity of precipitation change.

\subsection{Atmospheric Inputs}

The atmospheric response to changing magnetic conditions is not modeled self-consistently with the ionosphere-polar wind response. For the atmospheric densities and temperatures, we use the MSIS empirical model [Hedin et al., 1977]. Four geophysical cases are considered, including solar minimum $\left(F_{10.7}=70 \times 10^{-22} \mathrm{~W} \mathrm{~m}^{-2} \mathrm{~Hz}^{-1}\right)$ and solar maximum $\left(F_{10.7}=210\right.$ $\times 10^{-22} \mathrm{~W} \mathrm{~m}^{-2} \mathrm{~Hz}^{-1}$ ) for both summer (day 183) and winter (day 356) solstices. For the neutral wind pattern, we use the simple model discussed by Sojka et al. [1981]. With this model, the wind blows from 1300 LT over the polar region to 0100 LT. The wind speed at $F$ region heights is $55 \mathrm{~m} \mathrm{~s}^{-1}$ on the dayside and $250 \mathrm{~m} \mathrm{~s}^{-1}$ on the nightside. Near the terminator, the wind varies smoothly from the dayside to the nightside value. Note that the nightside wind is consistent with the "average" meridional wind measured in the dark polar cap by Meriwether et al. [1988].

During a geomagnetic storm, the neutral densities, temperatures, and winds can change appreciably, depending on the magnitude and duration of the storm and on the seasonal and solar cycle conditions. In our simulations, the atmospheric parameters change with time through the temporal change of the $A p$ magnetic index, which is an input to the mass spectrometer incoherent scatter (MSIS) empirical model. In general, however, the thermospheric changes during a storm can be larger than those predicted by MSIS. For our idealized storm, magnetic activity is enhanced during a 6-hour period, but the largest enhancement occurs during the first 3 hours, from 0430 to 0730 UT (Figure 2). At solar minimum, the time constant for accelerating the neutral atmosphere in and above the $F$ region is of the order of several hours to a day [Killeen et al., 1984], and therefore our neglect of the self-consistent atmospheric response should not affect our results. At solar maximum, on the other hand, the atmospheric response time is of the order of 1 to 3 hours. In this case, our neglect of the self-consistent atmospheric response could lead to quantitative errors, but we expect our results to be qualitatively correct. Also, recent model-data comparisons indicate that the coupled ionospherethermosphere models significantly overestimate electron density changes during stormis [Prölss et al., 1997], and it is not clear that a better quantitative result will be obtained with a selfconsistent thermosphere. At any rate, the inclusion of a selfconsistent thermosphere would greatly increase the CPU resources needed, which are already substantial.

\subsection{Trajectory Selection and Initial Conditions}

With our global model, convecting plasma flux tubes are followed as they move in response to magnetospheric electric fields (i.e., in response to the time varying Heppner-Maynard 


\section{Geomagnetic}

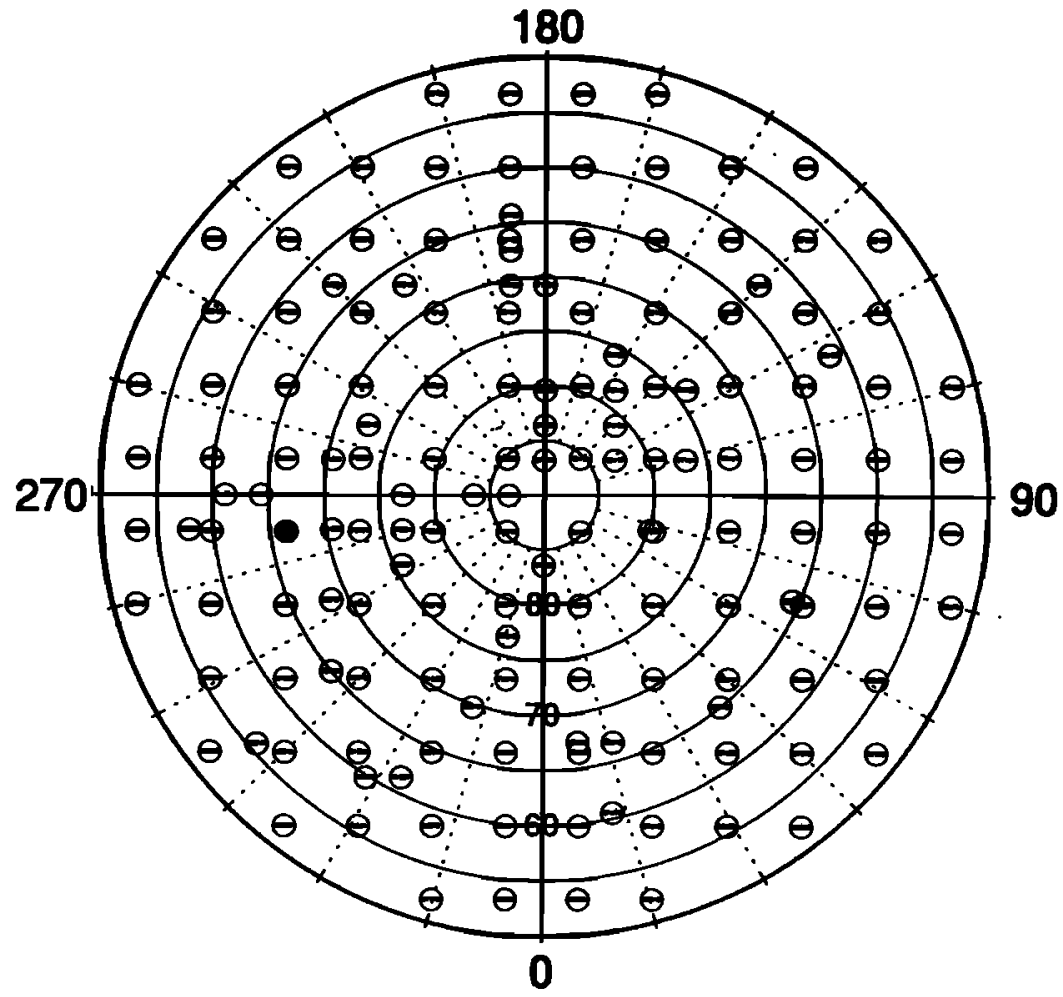

\section{Geomagnetic}

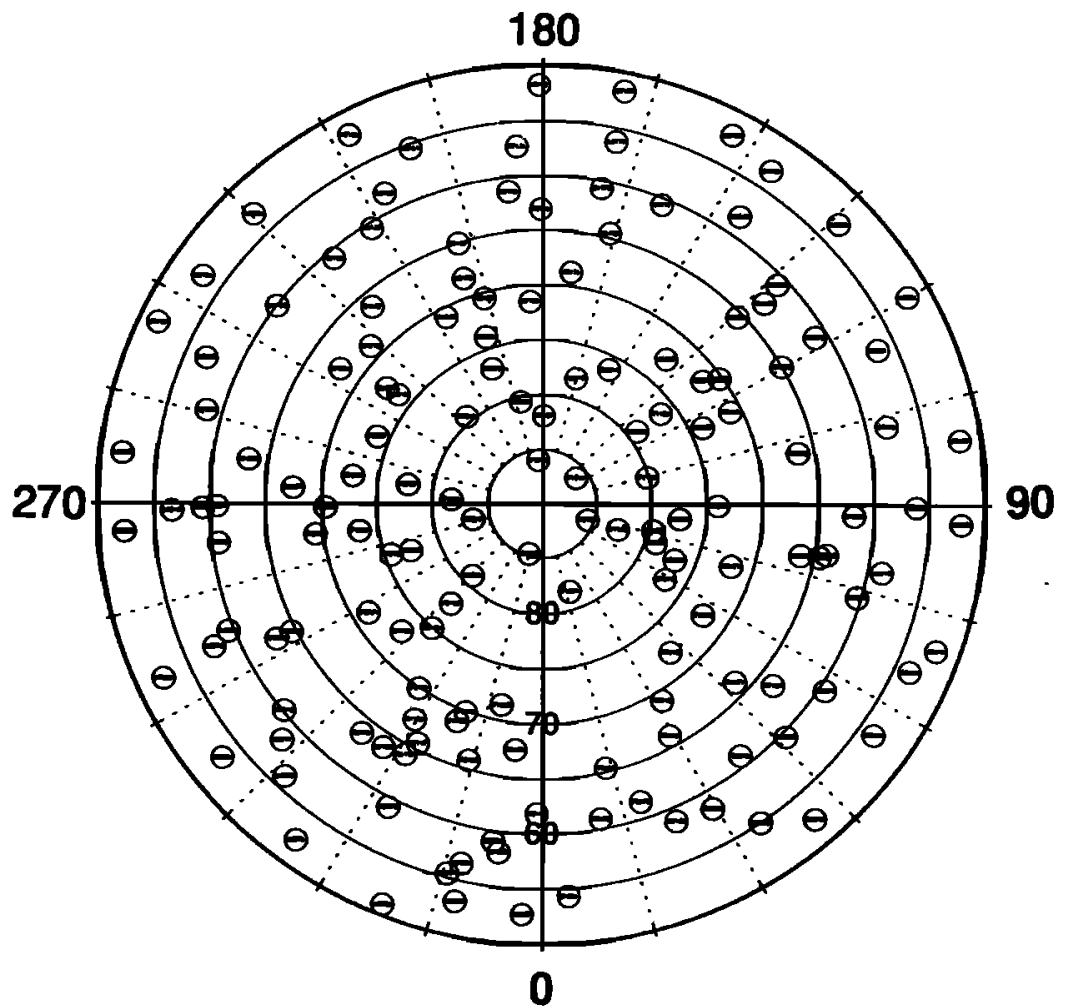

Figure 3. Locations of the 159 "polar wind" flux tubes at (top) 0300 UT and (bottom) 0600 UT. Throughout the simulation, the coverage in the polar region at high altitudes was similar to that shown in the two panels. At low altitudes, 1000 plasma flux tubes were followed. 


\section{$\mathrm{O}^{+}-500 \mathrm{~km}-0400 \mathrm{UT}$}
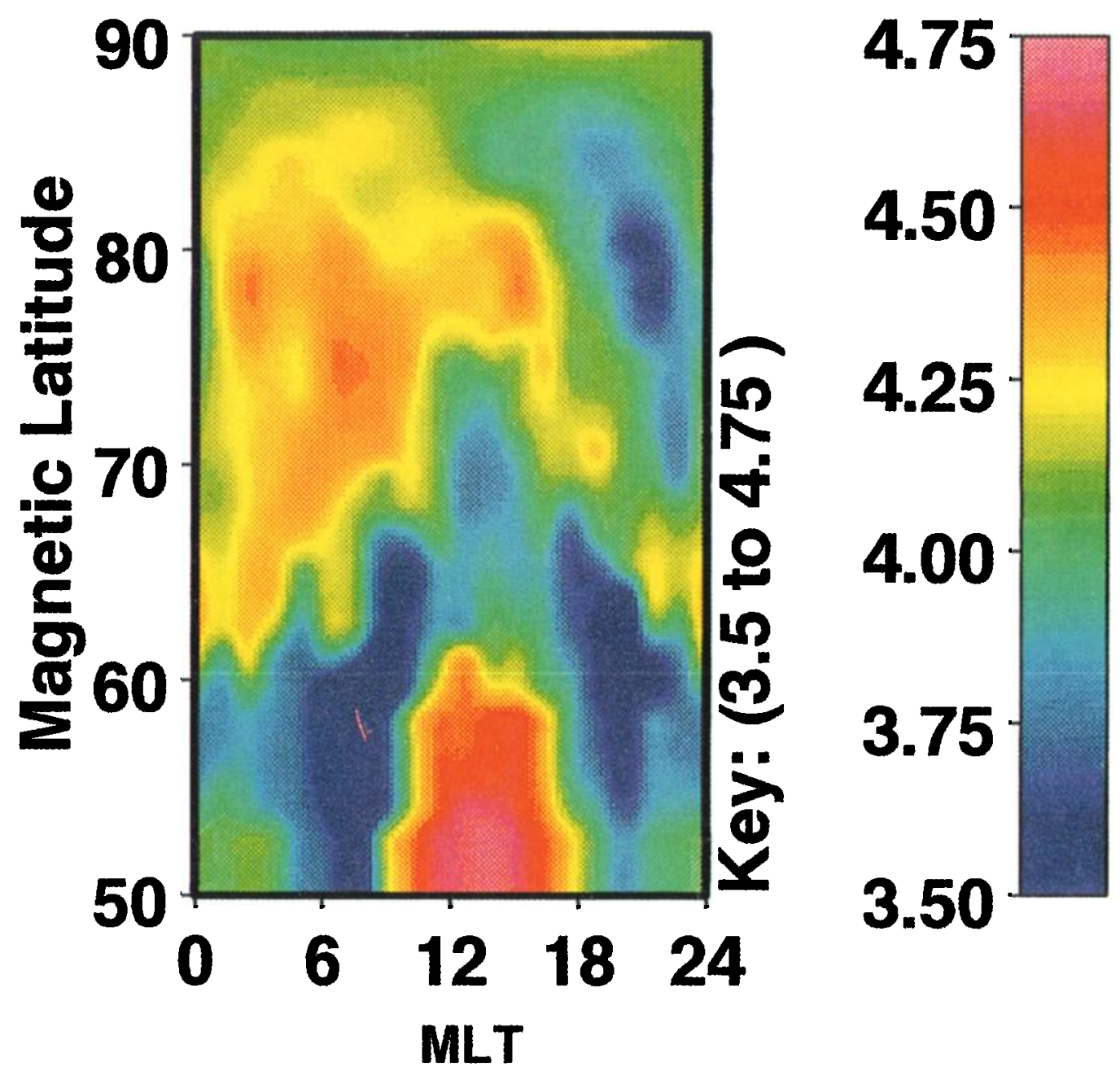

Plate 1. Snapshot of the $\mathrm{O}^{+}$density distribution at $0400 \mathrm{UT}$ and $500 \mathrm{~km}$ in a rectangular polar format. Magnetic latitude and MLT coordinates are used and the color coding corresponds to $\log _{10}\left[\mathrm{n}\left(\mathrm{O}^{+}\right), \mathrm{cm}^{-3}\right]$. The densities are for winter, solar minimum conditions.

convection pattern). Therefore the spatial resolution in latitude and longitude depends on the number of flux tubes selected. The low-altitude ionospheric model is, relatively speaking, computationally efficient and we were able to follow 1000 flux tubes for this study. The high-altitude hydrodynamic model, on the other hand, is CPU intensive, and therefore it was coupled to only 159 of the 1000 low-altitude flux tubes. Nevertheless, with a judicious choice of convecting flux tubes, it was possible to maintain good coverage of the polar region throughout the storm simulation. Figure 3 shows the locations of the 159 flux tubes at $0300 \mathrm{UT}$, which is prior to the storm, and at $0600 \mathrm{UT}$, which is during an active time when $K p=6$. Although the plasma flux tubes continually move, the coverage of the highlatitude domain remains fairly uniform.

To start a storm simulation, we first obtain a diurnally reproducible ionosphere-polar wind solution for a given set of geophysical conditions and $K p=1$. Then, at $0300 \mathrm{UT}$, we follow the $K p$ variation shown in Figure 2. For the four geophysical cases considered, the total CPU time used for this study is equivalent to 1320 hours on the CRAY XMP-processor. The disk storage requirements amounted to 1.6 Gbytes.

\subsection{Comparison With Previous Three- Dimensional Simulation Setup}

It is useful to compare our current storm simulation setup with that used previously [Schunk and Sojka, 1989]. In our first study, we only considered one geophysical case (solar minimum winter). We used a Heelis et al. [1982] "symmetric" two-cell convection pattern, a Spiro et al. [1982] auroral oval, the growth and decay of $K p$ were linear, and the maximum $K p$ was 8 . In this study, we consider four geophysical cases. The convection is an "asymmetric" two-cell pattern [Heppner and Maynard, 1987], the auroral oval is due to Hardy et al. [1985], the growth and decay of $K p$ are exponential, and the maximum $K p$ is 6 . Therefore, by comparing the present winter solar minimum case with our previous simulation, we can see the effects of using an asymmetric versus symmetric convection 


\section{$\mathrm{O}^{+}$- Winter - Solar Minimum}

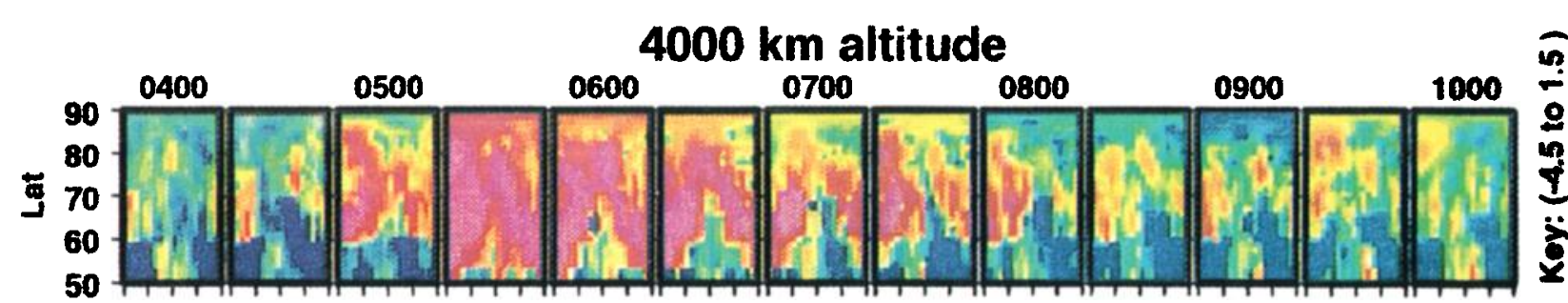

$1000 \mathrm{~km}$ altitude

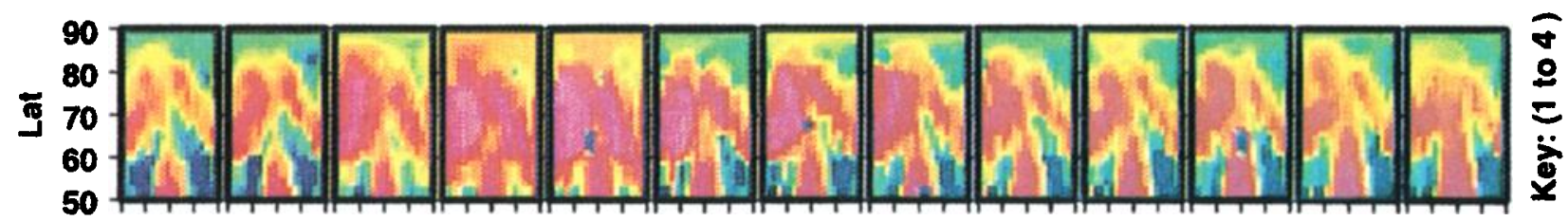

$500 \mathrm{~km}$ altitude

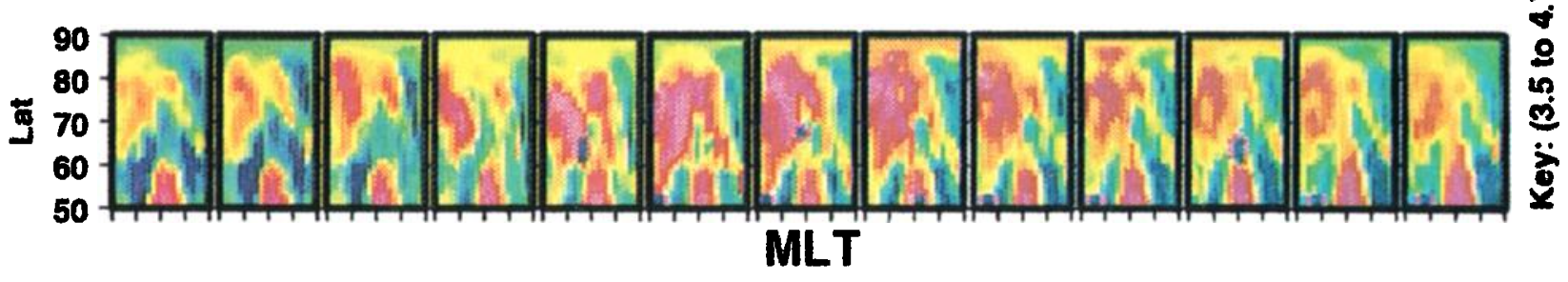

Plate 2a. Snapshots of the $\mathrm{O}^{+}$density distribution over the polar region at $500 \mathrm{~km}$ (bottom row), $1000 \mathrm{~km}$ (middle row) and $4000 \mathrm{~km}$ (top row) at a half-hour interval from 0400 to 1000 UT (left to right). Each rectangular plot extends from $50^{\circ}$ to $90^{\circ}$ magnetic latitude and 0-24 MLT. The $\mathrm{O}^{+}$densities are color coded with a fixed color key at each altitude, but there is a different color key at the different altitudes. The color keys correspond to an $\mathrm{O}^{+}$density variation of a factor of 20 at $500 \mathrm{~km}$, a factor of $10^{3}$ at $1000 \mathrm{~km}$, and a factor of $10^{6}$ at $4000 \mathrm{~km}$. The densities are for winter, solar minimum conditions.

pattern and an exponential versus linear $K p$ variation. Then, for a given geomagnetic storm scenario, we can determine the polar wind response for different seasonal and solar cycle conditions.

\section{Polar Wind Simulations}

The main focus of the study is on showing how the polar wind response to a geomagnetic storm varies with seasonal and solar cycle conditions. Although our global polar wind model covers the 90 to $9000 \mathrm{~km}$ altitude range, we will only present results for altitudes above $500 \mathrm{~km}$, which is the region where the $\mathrm{H}^{+}$outflow occurs. Also, numerous papers have been published on the response of the low-altitude ionosphere to a range of plasma convection and particle precipitation patterns, both constant and time varying, as well as to a wide range of geophysical conditions, and there is no need to reproduce those results [cf. Sojka, 1989; Roble and Ridley, 1994; Fuller-Rowell et al., 1988, and references therein].

It is, however, worth mentioning some of the important physical and chemical processes that occur in the ionosphere below $500 \mathrm{~km}$. It is well known that auroral electron precipitation leads to enhanced electron densities and temperatures [cf. Kelly, 1989]. Also, electric field heating results in elevated ion and neutral temperatures [Walker and Rees, 1968], bi-Maxwellian or toroidal ion velocity distributions [St.-Maurice and Schunk, 1979], and significant
$\mathrm{O}^{+}$to $\mathrm{NO}^{+}$composition changes [Schunk et al., 1975]. The latter process is particularly important in that a rapid conversion of $\mathrm{O}^{+}$into $\mathrm{NO}^{+}$acts to deplete the source of $\mathrm{H}^{+}$and can result in lower polar wind densities. All of these ionospheric processes are included in our polar wind simulations, but we will not discuss them here since they have been extensively described in previous publications.

In what follows, the storm variations for the different seasonal and solar cycle conditions will be displayed from different perspectives. First, because the polar wind can be highly dynamic and exhibit a complex temporal behavior, it is instructive to show the variations along a "representative" plasma flux tube as it convects across the polar region. Next, snapshots of the $\mathrm{H}^{+}$and $\mathrm{O}^{+}$density distributions at selected altitudes and as a function of time will be shown so that the global polar wind characteristics can be elucidated throughout the storm simulation. Finally, the total ion flow rate (ions $\mathbf{s}^{-1}$ ) over the entire polar region at selected altitudes as a function of time will be shown for both $\mathrm{H}^{+}$and $\mathrm{O}^{+}$.

\subsection{Solar Minimum Winter Simulation}

Figure 4 shows a representative convection trajectory in a magnetic latitude-MLT reference frame. At the start of the simulation (0300 UT), the plasma flux tube following this trajectory is located at about 1900 MLT and $67^{\circ}$ magnetic latitude (shown by the solid dot in Figure 3). Subsequently, the 


\section{$\mathrm{H}^{+}$- Winter - Solar Minimum}

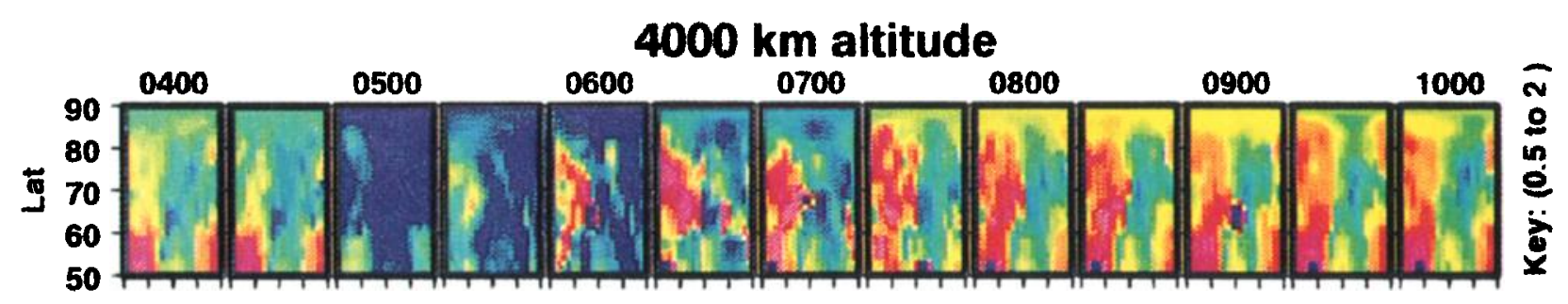

\section{$1000 \mathrm{~km}$ altitude}

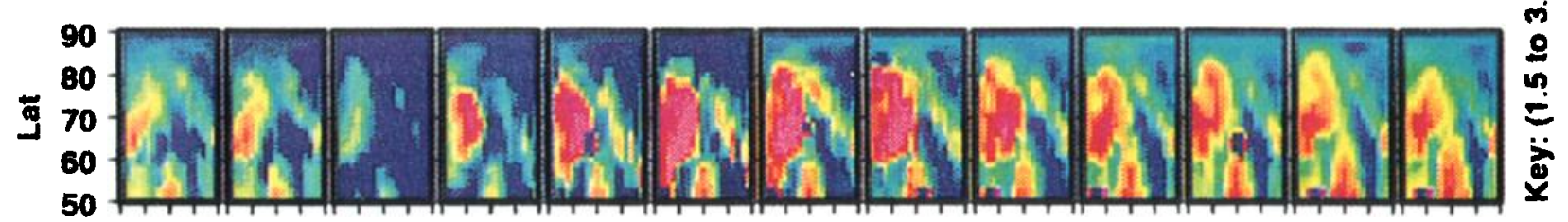

\section{$500 \mathbf{~ k m}$ altitude}

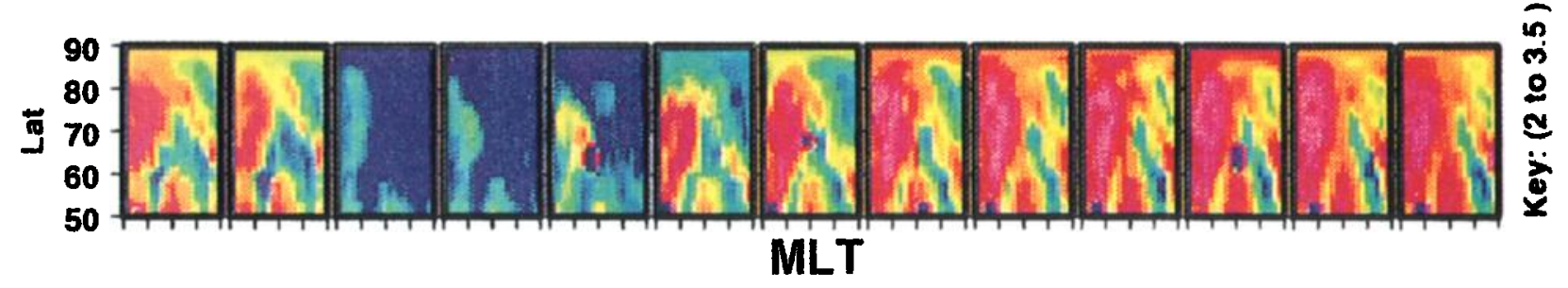

Plate 2b. Snapshots of the $\mathrm{H}^{+}$density distributions that are associated with the $\mathrm{O}^{+}$densities shown in Plate 2a. The plotting format is similar to that for Plate 2a. The color keys correspond to an $\mathrm{H}^{+}$density variation of a factor of 30 at $500 \mathrm{~km}$, a factor of 100 at $1000 \mathrm{~km}$, and a factor of 30 at $4000 \mathrm{~km}$.

plasma flux tube moves sunward and enters the dayside "storm" oval, passes through the convection throat, moves antisunward across the polar cap, enters the "quiet" nocturnal oval, and then leaves the evening oval near the end of the trajectory.

Figure 5a shows the temporal variations of the temperatures $\left(T_{e}, T_{i}, T_{n}\right)$, densities $\left(\mathrm{O}^{+}, \mathrm{O}, \mathrm{H}\right)$, and $\mathrm{O}^{+}$vertical velocity along the convection trajectory at an altitude of $500 \mathrm{~km}$. This altitude is selected for presentation because the $\mathrm{H}^{+}$outflow typically begins above this altitude and because it is one altitude where the ionospheric and polar wind models are coupled. The increase in $T_{e}$ to almost $4800 \mathrm{~K}$ between 0400 and $0600 \mathrm{UT}$ results from heating due to electron precipitation in the storm auroral oval. The increase in $T_{i}$ during this period is primarily a result of ion-neutral frictional heating in the region of large electric fields. These increases in $T_{e}$ and $T_{i}$ result in a substantial $\mathrm{O}^{+}$upflow, with $T_{e}$ being the main driver in this case because $T_{e}$ is substantially larger than $T_{i}$. Associated with the $\mathrm{O}^{+}$upflow is an $\mathrm{O}^{+}$density enhancement, but its peak lags behind that of the upflow because the $\mathrm{O}^{+}$upflow is a relatively slow diffusion process at and below $500 \mathrm{~km}$. The $\mathrm{H}^{+}$ions are in chemical equilibrium at $500 \mathrm{~km}$, and hence the $\mathrm{H}^{+}$velocity is negligibly small. The changes in the neutral densities and temperature are a result of the temporal variation of the magnetic activity index that is an input to the MSIS atmospheric model. Upon exiting the dayside oval, there is a rapid decrease in both $T_{e}$ and $T_{i}$ and, as a consequence, $\mathrm{O}^{+}$flows down as the topside ionosphere collapses. The $\mathrm{O}^{+}$flow remains downward at $500 \mathrm{~km}$ throughout most of the traversal of the polar cap, and associated with this downflow is a slow decay of the $\mathrm{O}^{+}$density (between 0600 and 0900 UT). These stormenhanced $\mathrm{O}^{+}$densities in the polar cap that persist after the storm lead to enhanced $\mathrm{H}^{+}$densities and escape fluxes at higher altitudes, and this results in a time delay in the buildup of the maximum global $\mathrm{H}^{+}$escape rate (to be discussed later). Finally, between about 0930 to $1400 \mathrm{UT}$, the convecting flux tube is in the "quiet" nighttime auroral oval. Here $T_{e}$ and $T_{i}$ are elevated, the $\mathrm{O}^{+}$flow is initially upward, and there is a slow buildup of the $\mathrm{O}^{+}$density at $500 \mathrm{~km}$, but the increases are smaller than what occurred in the daytime storm oval.

Figure 5b shows the temporal variation of the $\mathrm{H}^{+}$and $\mathrm{O}^{+}$ densities and drift velocities along the convection trajectory at $2500 \mathrm{~km}$ altitude. As the flux tube first enters the daytime storm oval, both the $\mathrm{H}^{+}$and $\mathrm{O}^{+}$flows are upward, with the drift velocity approaching $16 \mathrm{~km} \mathrm{~s}^{-1}$ for $\mathrm{H}^{+}$and $3.5 \mathrm{~km} \mathrm{~s}^{-1}$ for $\mathrm{O}^{+}$ (both ions are supersonic). After this initial surge, the $\mathrm{H}^{+}$drift velocity first decreases to $3.5 \mathrm{~km} \mathrm{~s}^{-1}$ and then increases to more than $20 \mathrm{~km} \mathrm{~s}^{-1}$. The $\mathrm{O}^{+}$ions, on the other hand, flow down shortly after 0500 UT, as they do at lower altitudes (Figure 5a). Despite the reversal in flow direction, $\mathrm{O}^{+}$is the "dominant ion" at $2500 \mathrm{~km}$ during most of the time that the magnetic activity is enhanced, from about 0430 to 0630 UT (Figure 2). The $\mathrm{O}^{+}$ density is also comparable to the $\mathrm{H}^{+}$density in the quiet nocturnal oval, where $T_{e}$ is elevated. Along the whole trajectory, the $\mathrm{H}^{+}$flow is upward at $2500 \mathrm{~km}$, but the $\mathrm{O}^{+}$flow is both upward and downward, which results in $\mathrm{H}^{+}-\mathrm{O}^{+}$ counterstreaming. Furthermore, the $\mathrm{H}^{+}$density displays a relatively slow variation, with $\mathrm{n}\left(\mathrm{H}^{+}\right) \sim 60 \mathrm{~cm}^{-3}$, while the $\mathrm{O}^{+}$ density varies by more than six orders of magnitude. 


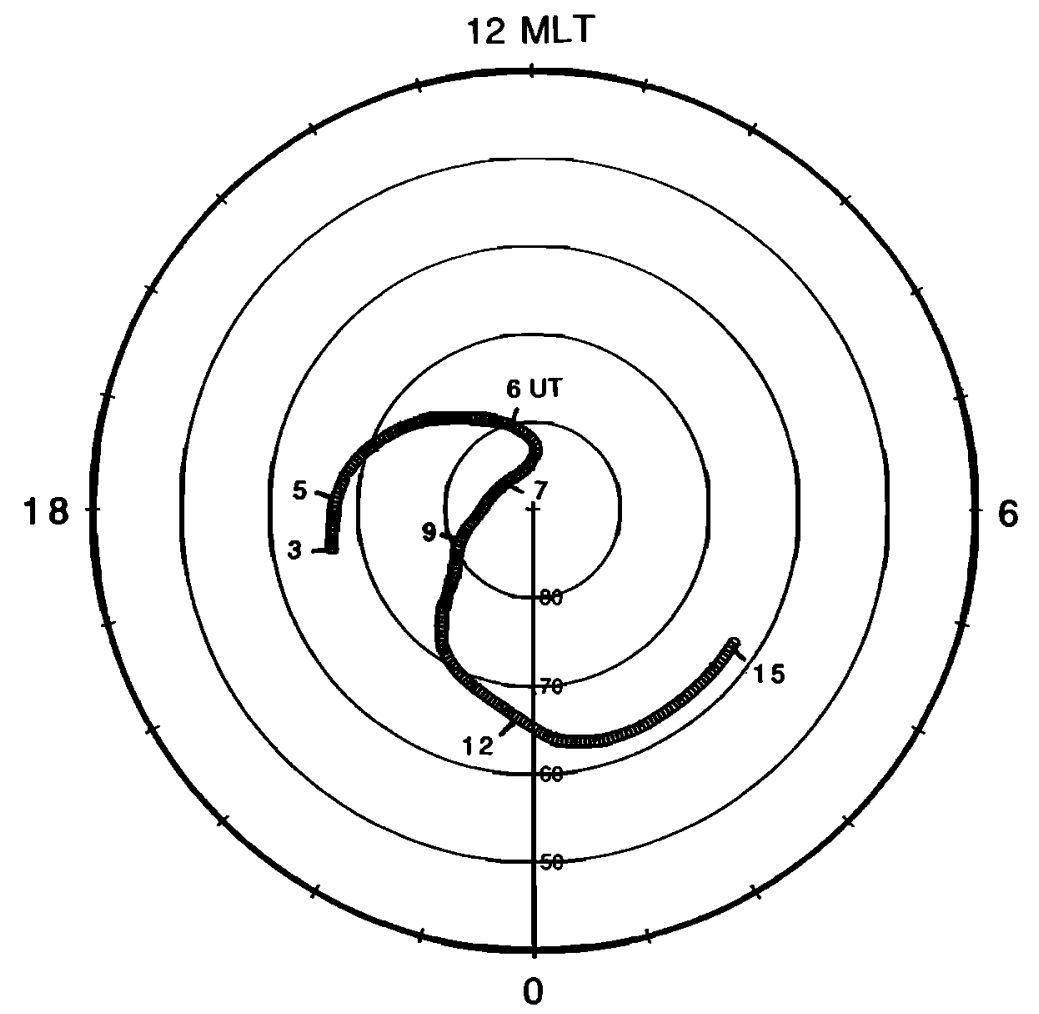

Figure 4. Convection trajectory of a representative flux tube of plasma during changing magnetic activity. At the start of the simulation the flux tube is located at about 1900 MLT and $67^{\circ}$ magnetic latitude, as shown by the solid dot in Figure 3. The tick marks along the trajectory indicate the times in universal time hours.

In order to display the "global" characteristics of the ionosphere-polar wind system as a function of altitude and time, it is converient to introduce a rectangular plotting format so that snapshots of the entire polar region can be stacked side-byside (different times) and on top of each other (different altitudes). Plate 1 shows a representative rectangular plot of the $\mathrm{O}^{+}$density distribution in the polar region for winter, solar minimum conditions. This plot corresponds to a snapshot of the $\mathrm{O}^{+}$density at $0400 \mathrm{UT}$ and $500 \mathrm{~km}$ altitude over the polar region from $50^{\circ}$ to $90^{\circ}$ magnetic latitude and 0000 to 2400 MLT. The density distribution is color coded, with red corresponding to high densities and blue to low densities. The high densities between 0800 to $1800 \mathrm{MLT}$ and $50^{\circ}-60^{\circ}$ latitude correspond to the dayside sunlit region. The low densities (blue) surrounding this region $\left(50^{\circ}-65^{\circ}\right.$ latitude; 1800 to 0900 MLT) is the main electron density trough. The moderate densities (yellow-red) between $65^{\circ}$ and $85^{\circ}$ latitude on the morningside ( 0100 to $1200 \mathrm{MLT}$ ) correspond to the auroral oval. Finally, the densities near the top of the plot are in the polar cap. Note that at 4 UT, which is just before the storm, the $\mathrm{O}^{+}$density variation over the polar region is about a factor of 20.

Plate 2a shows the global morphology of $\mathrm{O}^{+}$during and after the storm. Plate $2 a$ shows snapshots of the $\mathrm{O}^{+}$density distribution at $500 \mathrm{~km}$ (bottom row), $1000 \mathrm{~km}$ (middle row), and $4000 \mathrm{~km}$ (top row) at a half-hour interval from 0400 to 1000 UT. Each rectangular snapshot covers the entire polar region using the format shown in Plate 1. The bottom-left snapshot (0400 UT and $500 \mathrm{~km}$ ) is identical to Plate 1 . As before, red corresponds to high densities and blue to low densities, but the different altitudes have different color scales that are kept fixed throughout the storm simulation. This display is used so that one can quickly see the "relative" changes over the entire polar region as a function of time and altitude.

The primary features to be noted in Plate $2 \mathrm{a}$ are the time delays in the $\mathrm{O}^{+}$response to the storm. Initially, when the storm commences, there is an $\mathrm{O}^{+}$upwelling throughout the polar region in response to the elevated electron and ion temperatures, but there is a half-hour time delay associated with the $\mathrm{O}^{+}$density enhancement at high altitudes that is related to the $\mathrm{O}^{+}$transit time from low to high altitudes. During the peak of the storm (0500 to $0600 \mathrm{UT})$, there is a relative increase in the $\mathrm{O}^{+}$density throughout the polar region at both 1000 and $4000 \mathrm{~km}$ as the upwelling continues in response to the elevated plasma temperatures (positive storm effect), and then there is a relative decrease in $n\left(\mathrm{O}^{+}\right)$as the storm subsides and the temperatures decrease $(t>6.5$ hours). At $500 \mathrm{~km}$, however, $\mathrm{n}\left(\mathrm{O}^{+}\right)$displays a general increase from about 0500 to $0800 \mathrm{UT}$ due to the production of ionization at low altitudes associated with the ongoing precipitation and its subsequent diffusion to $500 \mathrm{~km}$. Hence the temporal variation of $n\left(\mathrm{O}^{+}\right)$is "opposite" at high and low altitudes between about 0600 to 0800 UT (i.e., during the storm's recovery phase).

Plate $2 b$ shows the global morphology of the $\mathrm{H}^{+}$density variation that is associated with the $\mathrm{O}^{+}$morphology shown in Plate 2a. The plotting format is similar for both plates. The primary feature to note is that shortly after the storm commences there is an " $\mathrm{H}^{+}$blowout" throughout the polar region at all altitudes as a consequence of the relatively large upward flow associated with the elevated electron and ion temperatures (see $0500 \mathrm{UT}$ ). This corresponds to a "negative storm effect" and is "opposite" to what happens to $\mathrm{O}^{+}$. The net 


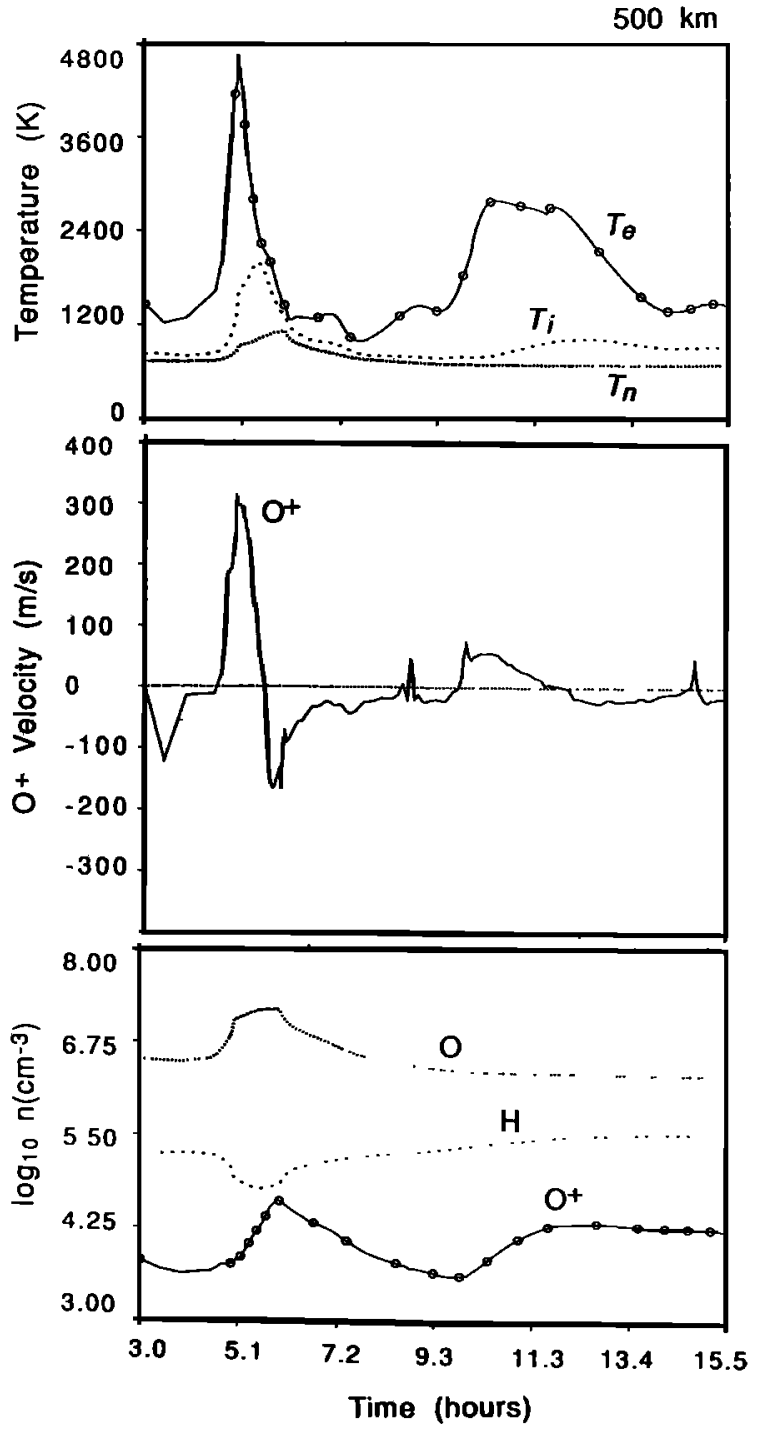

Figure 5a. Temporal variation of the (top) temperatures, (middle) $\mathrm{O}^{+}$vertical drift velocity, and (bottom) densities at $500 \mathrm{~km}$ for a plasma flux tube following the convection trajectory shown in Figure 4 . The results are for solar minimum winter conditions.

effect is that $\mathrm{O}^{+}$is the dominant ion at high altitudes $(4000 \mathrm{~km}$ ) throughout the polar region during enhanced magnetic activity (from about 0500 to 0630 UT). Subsequently, as the $\mathrm{O}^{+}$density builds up at low altitudes, the $\mathrm{H}^{+}$density increases due to the $\mathrm{O}^{+}$ $+\mathrm{H} \Leftrightarrow \mathrm{H}^{+}+\mathrm{O}$ reaction, but the relative increase occurs more quickly at $1000 \mathrm{~km}$ (morning oval at $0530 \mathrm{UT}$ ) than at either 500 or $4000 \mathrm{~km}$. Therefore, even though there is a negative storm effect at 500 and $4000 \mathrm{~km}$ throughout the polar region, the morning auroral oval displays a positive storm effect at $1000 \mathrm{~km}$, which indicates how complex storm variations can be. At $500 \mathrm{~km}$, on the other hand, the increase in $\mathrm{n}\left(\mathrm{H}^{+}\right)$after the storm occurs more gradually, following the $\mathrm{O}^{+}$density buildup that occurs with a 3 -hour time delay to achieve the maximum storm-associated densities.

The global morphologies of the $\mathrm{O}^{+}$and $\mathrm{H}^{+}$density variations are more evident in Plates $3 a$ and $3 b$. These plates have a format that is similar to Plates $2 a$ and $2 b$, except that more snapshots are presented. Specifically, snapshots over the entire polar region are shown at five altitudes $(500,1000,2000,4000$, and $8000 \mathrm{~km}$ ) and at a 5-min time interval from 0400 to $1000 \mathrm{UT}$ (i.e., 73 polar region plots at each altitude). Since each rectangular plot is small, the detailed features shown in Plates $2 \mathrm{a}$ and $2 \mathrm{~b}$ are lost, but the gross polar wind behavior as a function of altitude and time can be easily seen simply by observing the color variations. In particular, Plate $3 \mathrm{a}$ clearly shows the enhanced $\mathrm{O}^{+}$densities above $1000 \mathrm{~km}$ starting at 0515 UT and their subsequent slow decay after the storm. Plate $3 b$ shows the $\mathrm{H}^{+}$blowout that occurs prior to and during the time the $\mathrm{O}^{+}$density is enhanced at high altitudes, which results in $\mathrm{O}^{+}$ being the dominant ion at high altitudes over the bulk of the polar region from about 0515 to nearly 0800 UT (well after the storm's main phase). Also clearly seen in Plate $3 \mathrm{a}$ is the gradual buildup of the $\mathrm{O}^{+}$density at $500 \mathrm{~km}$. In addition, both figures show that the different altitudes display different response times due to the finite time it takes flow features to propagate from low to high altitudes.

Another parameter that is useful in discussing the global polar wind is the ion flow rate (ions $\mathrm{s}^{-1}$ ) across a given altitude integrated over latitudes greater than $50^{\circ}$ magnetic. The variation of this parameter versus time is shown in Figures $6 \mathrm{a}$ and $6 \mathrm{~b}$ for $\mathrm{O}^{+}$and $\mathrm{H}^{+}$, respectively. Figures $6 \mathrm{a}$ and $6 \mathrm{~b}$ show the ion flow rate at five altitudes $(500,1000,4000,7000$, and 8622 $\mathrm{km}$ ). It should be emphasized that at a given altitude and time, there are polar regions where the ions flow up and other regions where they flow down, and these have been integrated over to obtain the net flow rate.

During high magnetic activity (0430 to $0630 \mathrm{UT}$ ), the net $\mathrm{O}^{+}$ flow is initially upward and then it is downward, except at $\mathbf{8 6 2 2}$ km where it is upward throughout this time period. However, the $\mathrm{O}^{+}$flow rate at high altitudes is two orders of magnitude lower than at low altitudes. At $8622 \mathrm{~km}$, the maximum upward $\mathrm{O}^{+}$flow rate is $3 \times 10^{23}$ ions $\mathrm{s}^{-1}$, which occurs during the main phase of the storm (between 0500 and $0600 \mathrm{UT}$ ). For $\mathrm{H}^{+}$, on the other hand, the net flow rate is upward at all altitudes and times, and at $8622 \mathrm{~km}$ the flow rate corresponds to the global $\mathrm{H}^{+}$ escape rate. During the storm's growth phase, the $\mathrm{H}^{+}$flow rate decreases at all altitudes. It reaches a minimum at about 0500 UT and then increases throughout the main phase $(0500$ to 0600 UT). However, the maximum $\mathrm{H}^{+}$escape rate $\left(1.7 \times 10^{25}\right.$ ions $\mathrm{s}^{-1}$ ) occurs at $0700 \mathrm{UT}$, which is one hour after the storm's main phase. The reason for this behavior is as follows. Before the storm the polar wind is in equilibrium with the quiet underlying ionosphere. As magnetic activity increases, the associated increases in $T_{e}$ and $T_{i}$ act to increase the $\mathrm{H}^{+}$upward velocities and deplete the $\mathrm{H}^{+}$ions that constitute the initial polar wind (the $\mathrm{H}^{+}$blowout), and consequently, the global escape rate decreases with time. Subsequently, during the storm's main phase, the $\mathrm{O}^{+}$ density begins its gradual increase and this increasing source of $\mathrm{H}^{+}$accounts for the gradual increase in the $\mathrm{H}^{+}$escape rate. The time delay in the $\mathrm{O}^{+}$density buildup explains the delay in the establishment of the maximum global $\mathrm{H}^{+}$escape rate.

\subsection{Solar Maximum Summer Simulation}

With regard to geophysical conditions, this solar maximum summer case is opposite to the solar minimum winter case discussed in the previous subsection. However, except for the change of $F_{10.7}$ from 70 to 210 and the day number from 356 to 183 , the storm simulation is the same as in the previous case. The main differences in the two cases are that the bulk of the polar region is sunlit in summer and that the neutral atmosphere 


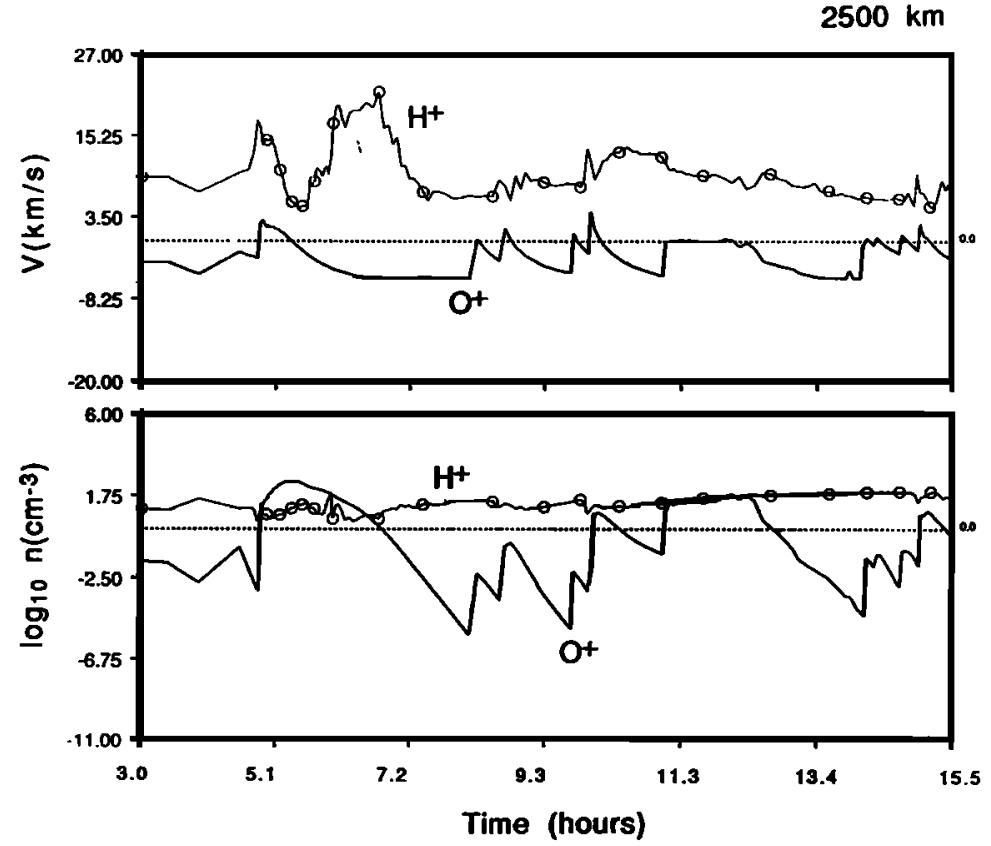

Figure 5b. Temporal variation of the (top) ion vertical drift velocities and (bottom) densities at $2500 \mathrm{~km}$ for a plasma flux tube following the convection trajectory shown in Figure 4. The results are for solar minimum winter conditions.

is significantly different. These differences, in turn, lead to significantly different $\mathrm{H}^{+}$and $\mathrm{O}^{+}$densities, drift velocities, and temperatures.

These differences are shown in Figure 7a, where the temporal variations of the temperatures $\left(T_{e}, T_{i}, T_{n}\right)$, densities $\left(\mathrm{O}^{+}, \mathrm{O}, \mathrm{H}\right)$, and $\mathrm{O}^{+}$vertical velocity are shown at an altitude of $500 \mathrm{~km}$ for a flux tube of plasma following the convection trajectory in Figure 4. A careful comparison of the two-geophysical cases (Figures 5a and 7a) indicates that at solar maximum summer $T_{n}$ is a factor of 2 higher, atomic oxygen is a factor of 11 higher, $\mathrm{O}^{+}$is a factor of 22 higher, and atomic hydrogen is a factor of 18 lower than the corresponding values at solar minimum winter. The net effect is that the $\mathrm{H}^{+}$density at $500 \mathbf{~ k m}$ is about a factor of 10 lower at solar maximum summer than at solar minimum winter. On the other hand, the peak upward $\mathrm{O}^{+}$velocity during the storm at solar maximum summer $(100 \mathrm{~m} / \mathrm{s})$ is not that different than the peak value at solar minimum winter $(300 \mathrm{~m} / \mathrm{s})$. Since the $\mathrm{O}^{+}$density is 22 times larger at solar maximum summer, a much larger upward $O^{+}$flux occurs at solar maximum summer than at solar minimum winter. For example, at $800 \mathrm{~km}$ the upward $\mathrm{O}^{+}$flux approaches $4 \times 10^{9} \mathrm{~cm}^{-2} \mathrm{~s}^{-1}$ at solar maximum summer and only about $2 \times 10^{8} \mathrm{~cm}^{-2} \mathrm{~s}^{-1}$ at solar minimum winter for the plasma flux tube following the trajectory in Figure 4 (this result is not shown). However, when $T_{e}$ decreases and the topside ionosphere collapses, the downward $\mathrm{O}^{+}$flux at $800 \mathrm{~km}$ is greater than $10^{9} \mathrm{~cm}^{-2} \mathrm{~s}^{-1}$ in both geophysical cases.

Figure $7 \mathrm{~b}$ shows the temporal variation of the $\mathrm{H}^{+}$and $\mathrm{O}^{+}$ densities and drift velocities along the convection trajectory at $2500 \mathrm{~km}$ altitude. Comparing these to the solar minimum winter case (Figure $5 b$ ) reveals some important differences. First, for solar maximum summer $\mathrm{O}^{+}$is the dominant ion at all times at this altitude, with the $\mathrm{O}^{+}$density approaching $6 \times 10^{3}$ $\mathrm{cm}^{-3}$ during the storm, whereas for the solar minimum winter case the $\mathrm{O}^{+}$density is typically several orders of magnitude lower than the $\mathrm{H}^{+}$density. Next, the magnitudes of the $\mathrm{H}^{+}$and
$\mathrm{O}^{+}$velocities are generally smaller for solar maximum summer than for solar minimum winter. Finally, it should be noted that although the $\mathrm{H}^{+}$density at $500 \mathrm{~km}$ is about a factor of 10 lower at solar maximum summer than at solar minimum winter, at $2500 \mathrm{~km}$ it is only slightly lower (30 versus $50 \mathrm{~cm}^{-3}$ ). This indicates that a substantial amount of $\mathrm{H}^{+}$is produced at high altitudes for solar maximum summer due to the elevated $\mathrm{O}^{+}$ densities.

The global morphology of the $\mathrm{O}^{+}$density distribution in the polar region for the summer solar maximum case is shown in Plate $4 \mathrm{a}$, where snapshots are shown at three altitudes (500, 1000 and $4000 \mathrm{~km}$ ) and at a half-hour interval from 0400 to 1000 UT. As before, red corresponds to high densities and blue to low densities. In summer, the bulk of the polar region is sunlit, and hence the densities are greater and the density distribution is more uniform than in winter. For example, at $500 \mathrm{~km}$ and $0400 \mathrm{UT}$, the $\mathrm{O}^{+}$density varies by only a factor of 4 over the polar region, whereas for the winter case the variation is a factor of 20 (Plate 1). The primary feature seen in Plate 4a is that during the peak of the storm (0500 to 0630 UT) there is an increase in the $\mathrm{O}^{+}$density in the polar region at $4000 \mathrm{~km}$ (positive storm effect), while at $500 \mathrm{~km}$ there is a decrease (negative storm effect). That is, the temporal morphologies are opposite at high and low altitudes. The temporal morphologies are also opposite during and after the storm's recovery phase, but they are reversed. Then, the $\mathrm{O}^{+}$density decreases at high altitudes and increases at low altitudes due primarily to the downflow associated with the decreasing plasma temperatures. Note that these results are different from what occurs for winter solar minimum conditions. In that case, the $\mathrm{O}^{+}$density increases at all altitudes during the peak of the storm, and only in the recovery phase are the temporal morphologies opposite at high and low altitudes.

Plate 4b shows the global morphology of the $\mathrm{H}^{+}$density variation that is associated with the $\mathrm{O}^{+}$morphology shown in Plate 4a. The main feature to note is that during the peak of the 


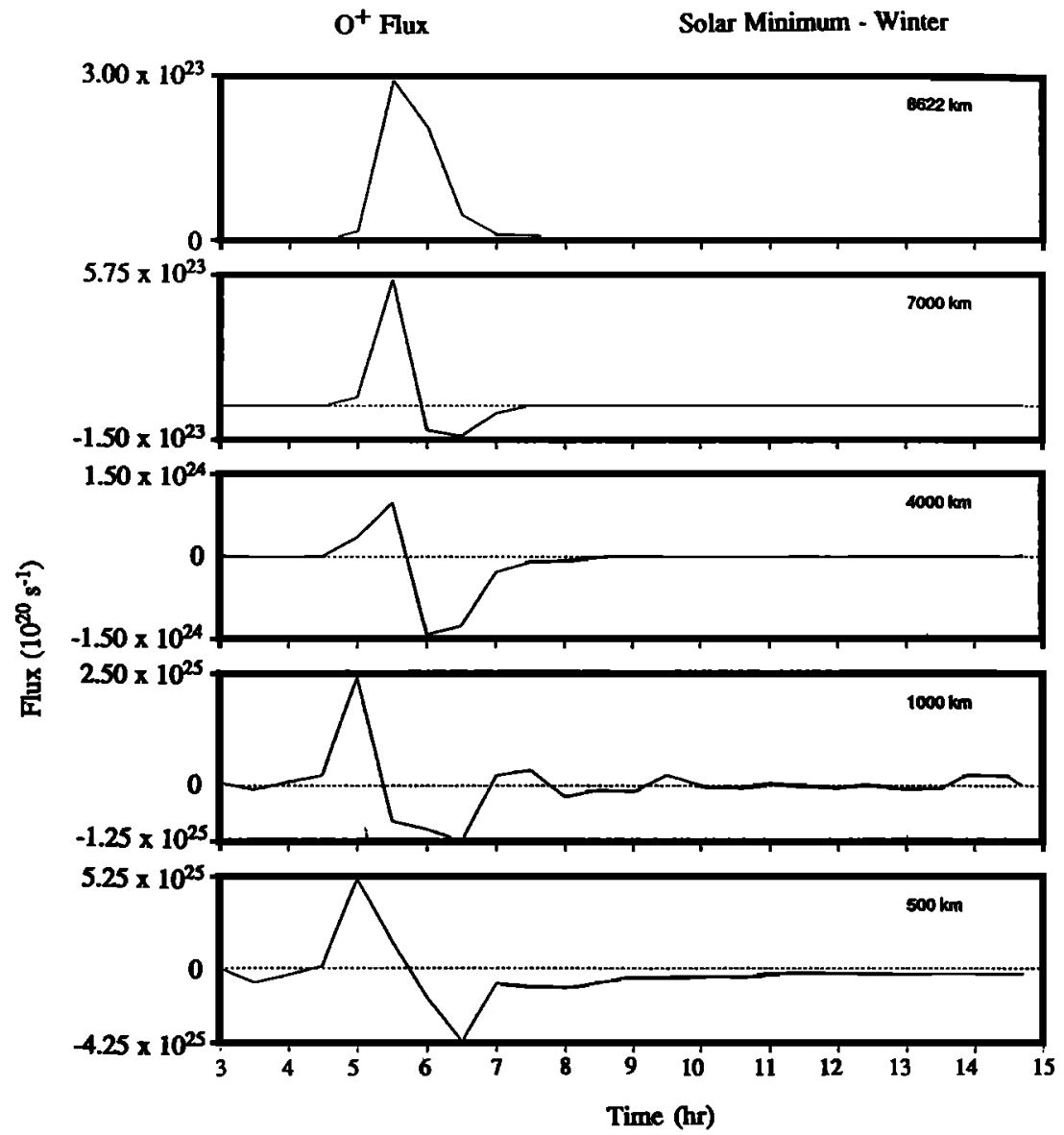

Figure 6a. $\mathrm{O}^{+}$flow rate (ions $\mathrm{s}^{-1}$ ) as a function of time at selected altitudes. The flow rate is obtained by integrating the $\mathrm{O}^{+}$flux over the entire polar region at each altitude. The results are for winter solar minimum conditions.

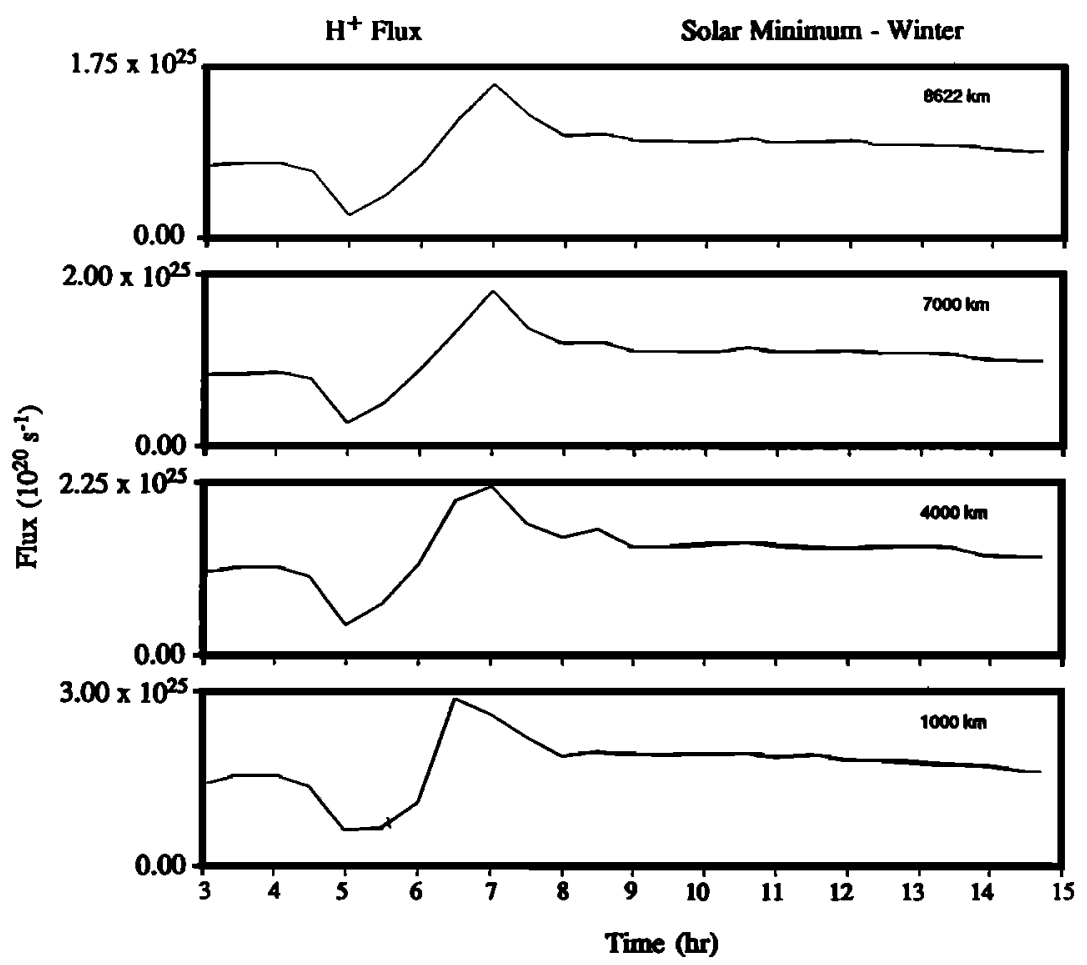

Figure $6 \mathrm{~b} . \mathrm{H}^{+}$flow rate (ions $\mathrm{s}^{-1}$ ) as a function of time at selected altitudes. The flow rate calculations and geophysical conditions are the same as for Figure 6 a. 

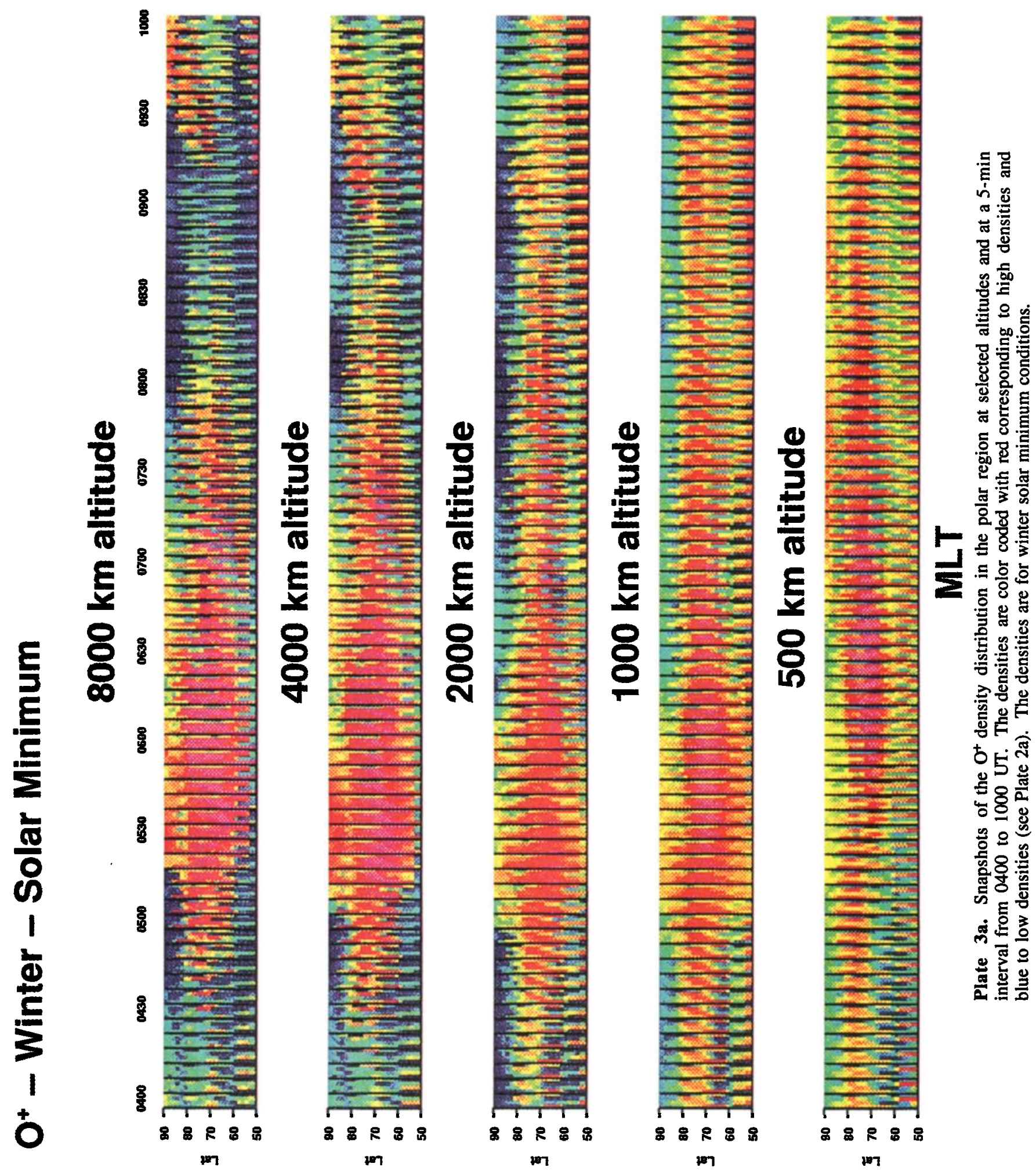

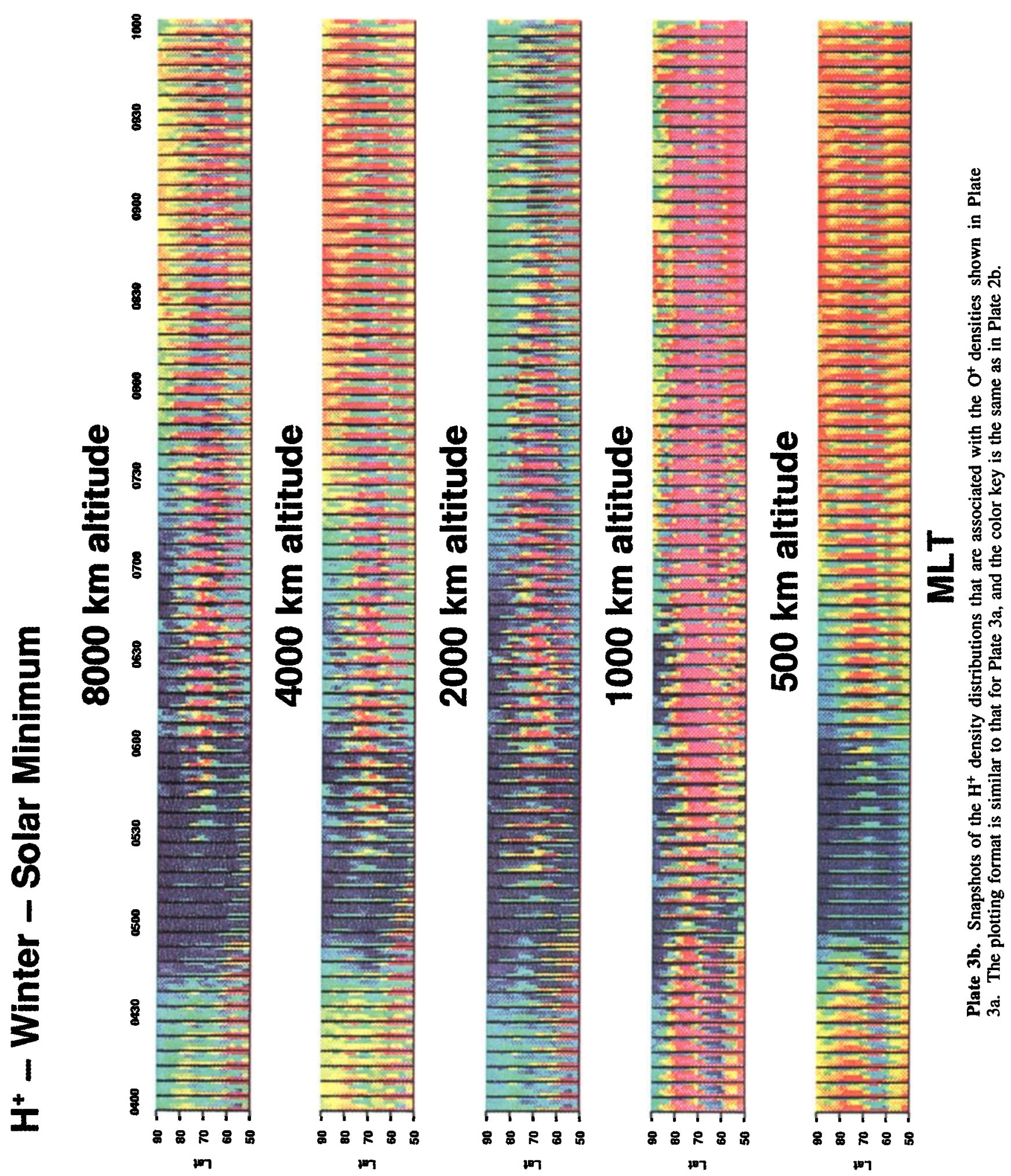


\section{$\mathrm{O}^{+}$- Summer - Solar Maximum}
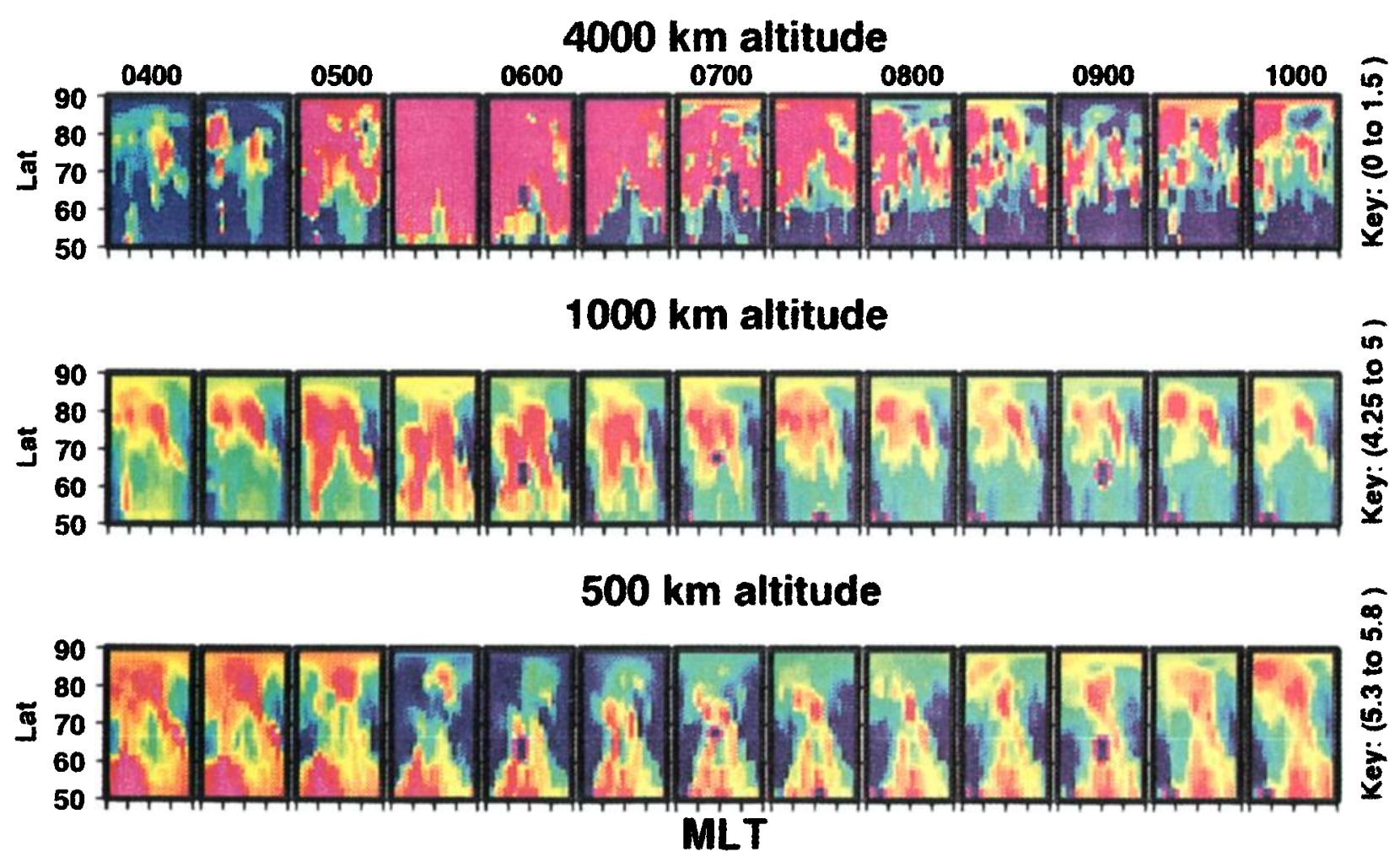

Plate 4a. Snapshots of the $\mathrm{O}^{+}$density distribution over the polar region at $500 \mathrm{~km}$ (bottom row), $1000 \mathrm{~km}$ (middle row), and $4000 \mathrm{~km}$ (top row) at a half-hour interval from 0400 to 1000 UT (left to right). Each rectangular plot extends from $50^{\circ}$ to $90^{\circ}$ magnetic latitude and 0-24 MLT. The color key is fixed at a given altitude, but it is different at the different altitudes. The color keys correspond to an $\mathrm{O}^{+}$density variation of a factor of 4 at $500 \mathrm{~km}$, a factor of 6 at $1000 \mathrm{~km}$, and a factor of 30 at $4000 \mathrm{~km}$. The densities are for summer, solar maximum conditions.

storm (0500 to 0630 UT) the $\mathrm{H}^{+}$density in the polar region increases at $4000 \mathrm{~km}$ and decreases at $500 \mathrm{~km}$ (opposite behavior). In and after the storm's recovery phase, the trend is reversed. The $\mathrm{H}^{+}$density basically decreases at $4000 \mathrm{~km}$ and slowly increases at $500 \mathrm{~km}$. This general behavior of the $\mathrm{H}^{+}$ density morphology is the same as that exhibited by $\mathrm{O}^{+}$(Plate $4 a)$, i.e., the ions vary in phase for summer solar maximum conditions, and this is due primarily to the fact that $\mathrm{H}^{+}$is in chemical equilibrium with $\mathrm{O}^{+}$to a relatively high altitude because of the large $\mathrm{O}^{+}$and atomic oxygen densities that occur for these conditions. However, this is again different from the $\mathrm{H}^{+}$behavior for winter solar minimum conditions, where an $\mathrm{H}^{+}$ density blowout occurs during the peak of the storm.

Birds-eye views of the $\mathrm{O}^{+}$and $\mathrm{H}^{+}$density morphologies are shown in Plates 5a and 5b, respectively, where snapshots of the entire polar region are shown at five altitudes and at a 5-min time interval from 0400 to $1000 \mathrm{UT}$. Clearly evident are the $\mathrm{O}^{+}$ and $\mathrm{H}^{+}$density decreases at $500 \mathrm{~km}$ during the storm's peak and the density increases at $4000 \mathrm{~km}$. However, Plate 5 a shows that the $\mathrm{O}^{+}$density increases at all altitudes above about $1000 \mathrm{~km}$ during the storm, but there are time delays associated with both the buildup and decay of the enhanced $\mathrm{O}^{+}$densities that vary with altitude. The $\mathrm{H}^{+}$temporal behavior at high altitudes is similar to that of $\mathrm{O}^{+}$, but not as clear.

A careful comparison of the $\mathrm{H}^{+}$and $\mathrm{O}^{+}$densities at high altitudes (Plate 4a versus $4 \mathrm{~b}$; Plate $5 \mathrm{a}$ versus $5 \mathrm{~b}$ ) indicates that for summer solar maximum conditions $\mathrm{O}^{+}$is the dominant ion to altitudes up to $8000 \mathrm{~km}$ throughout the polar region during enhanced geomagnetic activity. This is a significant result because only the classical polar wind has been modeled; i.e., no high-altitude energy sources have been included. This subject will be discussed in more detail later.

With regard to the ion flow rate across a given altitude, the temporal variation of the $\mathrm{O}^{+}$flow rate for summer solar maximum is qualitatively very similar to that shown in Figure $6 \mathrm{a}$ for winter solar minimum. This is the case for each of the selected altitudes in Figure 6a. However, the $\mathrm{O}^{+}$flow rates are larger for summer solar maximum than for winter solar minimum. For example, during the storm, the maximum upward $\mathrm{O}^{+}$flow rate at $8622 \mathrm{~km}$ is $3 \times 10^{23}$ ions $\mathrm{s}^{-1}$ for winter solar minimum (Figure 6a) and $2 \times 10^{24}$ ions $\mathrm{s}^{-1}$ for summer solar maximum (not shown). For $\mathrm{H}^{+}$, on the other hand, the temporal variation of the flow rate is not that similar for summer solar maximum (Figure 8) to that for winter solar minimum (Figure 6b). Also, at each altitude, the $\mathrm{H}^{+}$flow rates for summer solar maximum are lower, by a factor of from 3 to 5 , than those for winter solar minimum.

\subsection{Solar Maximum Winter Simulation}

The comparison of this case with the two previous cases leads to some interesting results in that the qualitative and quantitative comparison can match different cases. Considering $\mathrm{O}^{+}$first, the density distribution in the polar region displays a 


\section{$\mathrm{H}^{+}$- Summer - Solar Maximum}
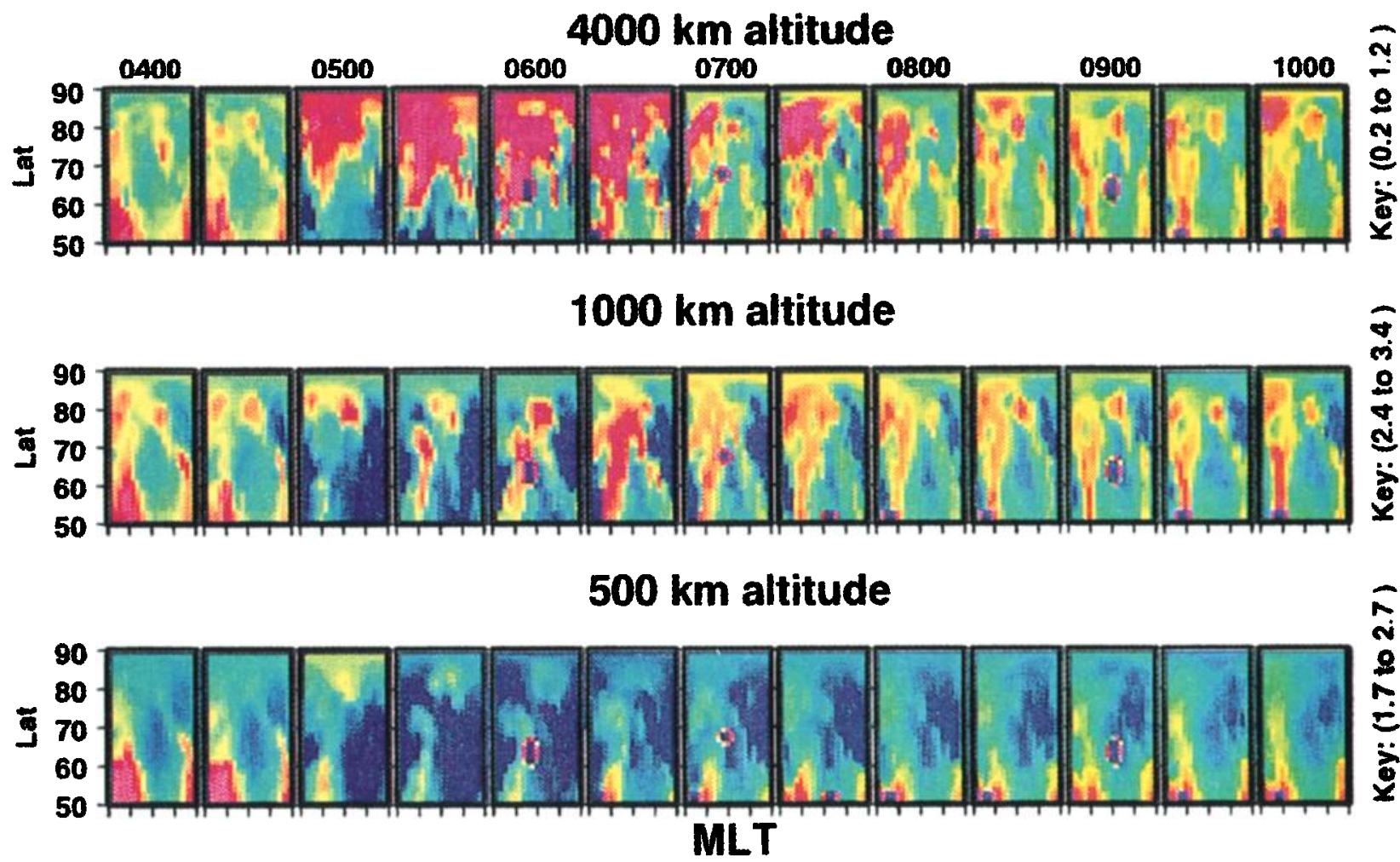

Plate 4b. Snapshots of the $\mathrm{H}^{+}$density distributions that are associated with the $\mathrm{O}^{+}$densities shown in Plate 4a. The color keys correspond to an $\mathrm{H}^{+}$density variation of a factor of 10 at each altitude, but the absolute densities decrease with altitude.

variation with time and altitude that is "qualitatively" very similar to that shown in Plate 5a for solar maximum summer. That is, at $1000,2000,4000$ and $8000 \mathrm{~km}$ there is an increase in the $\mathrm{O}^{+}$density during enhanced magnetic activity $(0500$ to 0630 UT), while there is a decrease at $500 \mathrm{~km}$ (the decrease is more extensive for this case of solar maximum winter). However, the total $\mathrm{O}^{+}$flow rate displays a temporal variation that is not too similar to either of the previous geophysical cases, but "quantitatively" the values are similar to those obtained for the solar minimum winter case. For example, at $8622 \mathrm{~km}$ the peak $\mathrm{O}^{+}$flow rate during the storm is $3 \times 10^{23}$ ions $\mathrm{s}^{-1}$ for solar minimum winter (Figure 6a) and $4.25 \times 10^{23}$ ions $\mathrm{s}^{-1}$ for this case of solar maximum winter.

For $\mathrm{H}^{+}$, the density distribution in the polar region displays a variation with time and altitude that is "qualitatively" very similar to that shown in Plate $3 b$ for solar minimum winter conditions. In particular, the $\mathrm{H}^{+}$density is significantly reduced at all altitudes during enhanced magnetic activity. Likewise, the temporal variation of the total $\mathrm{H}^{+}$flow rate is qualitatively similar to the solar minimum winter case (Figure 6b), but quantitatively the values are similar to the solar maximum summer case (Figure 8 ). The $\mathrm{H}^{+}$peak flow rate during the storm is $4.75 \times 10^{24}$ ions $\mathrm{s}^{-1}$ for solar maximum summer and $5 \times 10^{24}$ ions $\mathrm{s}^{-1}$ for this case of solar maximum winter.

\subsection{Solar Minimum Summer Simulation}

The comparison of this case with the two main cases discussed in subsections $\mathbf{4 . 1}$ and $\mathbf{4 . 2}$ again yields different results for $\mathrm{O}^{+}$and $\mathrm{H}^{+}$. The $\mathrm{O}^{+}$density distribution in the polar region displays a variation with time and altitude that is qualitatively very similar to the behavior for solar minimum winter conditions (Plate 3a). That is, there is an $O^{+}$density buildup at all altitudes throughout the bulk of the polar region from about 0530 to $0630 \mathrm{UT}$. For $\mathrm{H}^{+}$, on the other hand, the temporal variation of its density distribution versus altitude and time is qualitatively more similar to the behavior for solar maximum summer conditions (Plate 5 b).

\subsection{Summary of Qualitative Stormtime Behavior}

With regard to the variation of the ion density distributions in the polar region, the following results are obtained. For $\mathrm{O}^{+}$, the stormtime variations in summer and in winter are qualitatively similar at solar maximum and they are qualitatively similar at solar minimum. However, the stormtime variations are different at solar maximum and minimum; i.e., for $\mathrm{O}^{+}$the solar cycle trend is more important. For $\mathrm{H}^{+}$the stormtime variations at solar minimum and maximum are qualitatively similar in winter and again in summer, but they differ in winter and summer. That is, for $\mathrm{H}^{+}$the seasonal trend is more important.

\section{Summary and Discussion}

A time-dependent, three-dimensional, multi-ion model of the global ionosphere-polar wind system was used to determine the system's response to an idealized geomagnetic storm for 
different seasonal and solar cycle conditions. The model covers the altitude range from 90 to $9000 \mathrm{~km}$ for latitudes greater than $50^{\circ}$ in the northern hemisphere. At low altitudes (90 to 800 $\mathrm{km})$, three-dimensional density $\left(\mathrm{NO}^{+}, \mathrm{O}_{2}^{+}, \mathrm{N}_{2}^{+}, \mathrm{O}^{+}, \mathrm{N}^{+}\right)$and temperature $\left(T_{e}, T_{i l l}, T_{i \perp}\right)$ distributions were obtained from a numerical solution of the appropriate continuity, momentum, and energy equations. At high altitudes (500 to $9000 \mathrm{~km}$ ), the time-dependent, nonlinear, hydrodynamic equations for $\mathrm{H}^{+}$and $\mathrm{O}^{+}$were solved self-consistently with the ionospheric equations taking into account collisions, charge exchange chemical reactions, flux tube divergence, and ion temperature anisotropies. The model can describe supersonic ion flow, shock formation, and ion energization during plasma expansion events.

Four storm simulations of the "classical" polar wind were conducted, corresponding to winter and summer solstices at both solar maximum and minimum. For each simulation, the magnetic activity level changed from quiet to active and then back to quiet again over a 5 -hour period. When the activity
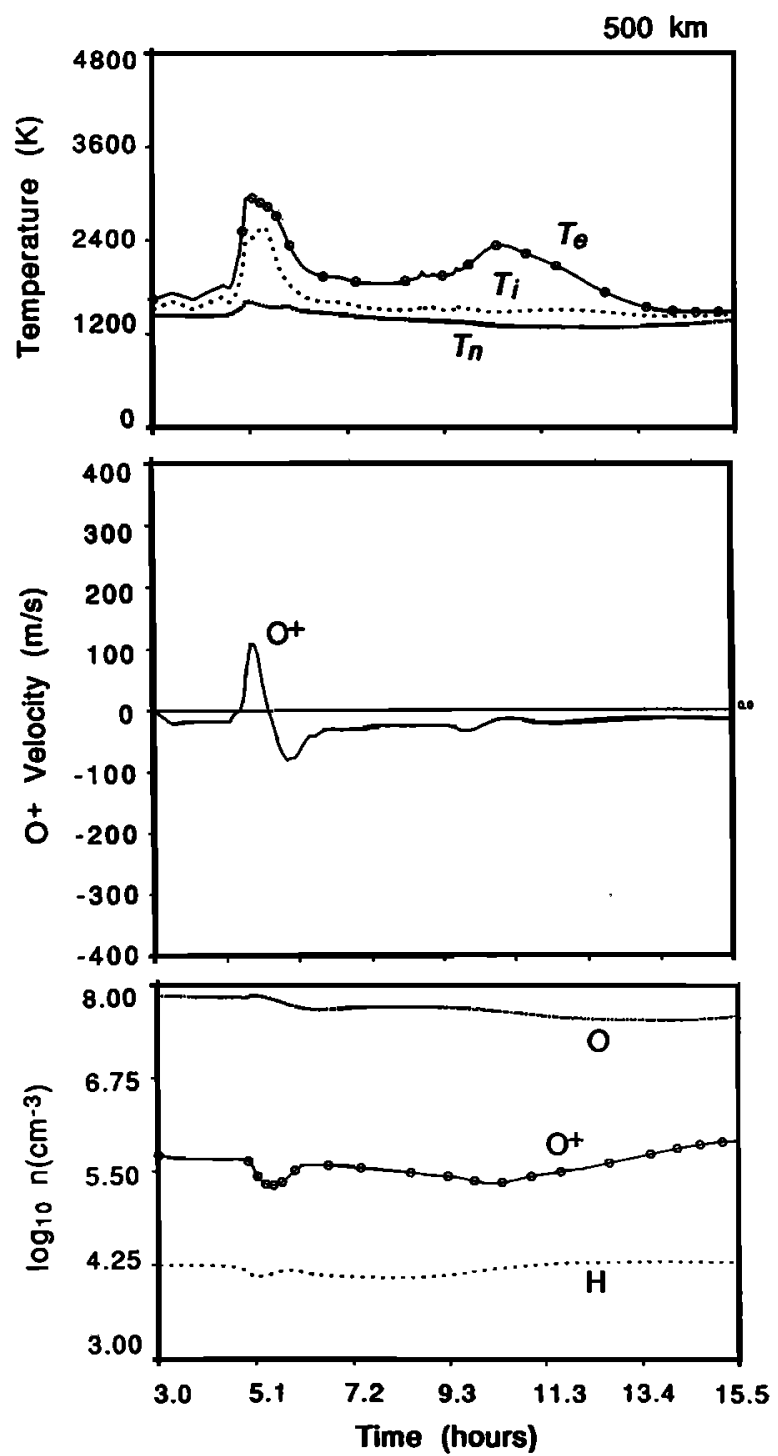

Figure 7a. Temporal variation of the (top) temperatures, (middle) $\mathrm{O}^{+}$vertical velocities, and (bottom) densities at 500 $\mathrm{km}$ for a plasma flux tube following the trajectory shown in Figure 4. The results are for solar maximum summer conditions.
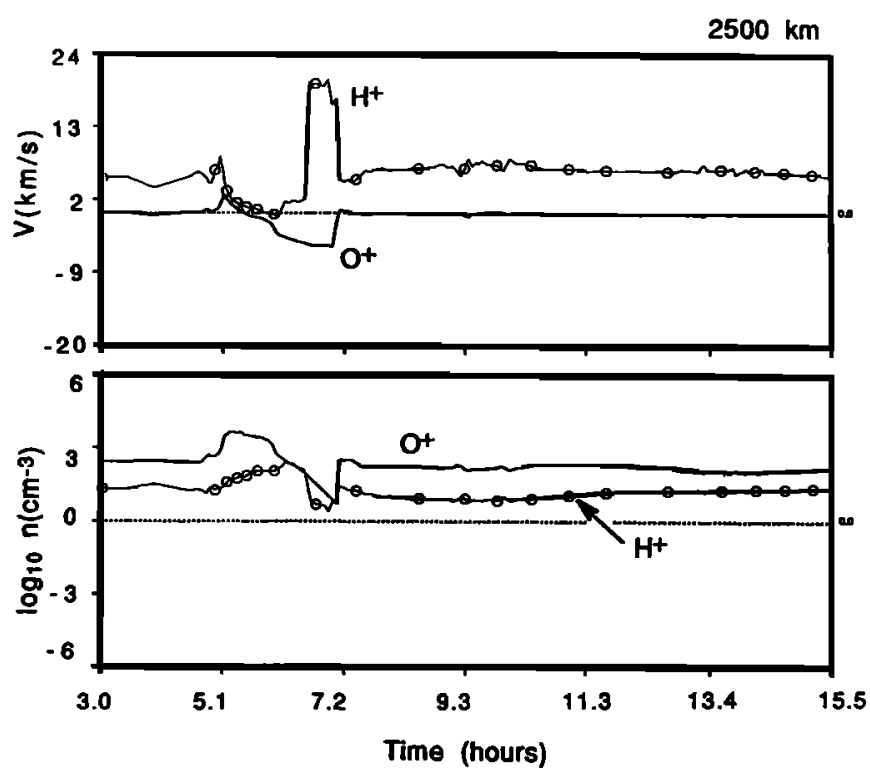

Figure 7b. Temporal variation of the (top) ion vertical drift velocities and (bottom) densities at $2500 \mathrm{~km}$ for a plasma flux tube following the convection trajectory shown in Figure 4. The results are for solar maximum summer conditions.

level increased, the auroral oval and plasma convection pattern expanded, particle precipitation became more intense, and the convection electric field strengths increased. The reverse occurred during declining magnetic activity. Throughout the storm period, the ionosphere-polar wind system was in a continual state of horizontal motion, with the plasma convecting into and out of sunlight, the cusp, the polar cap, the nocturnal oval, and the main trough.

\subsection{Summary}

The following results are common to all four of the geophysical cases considered:

1. Plasma pressure disturbances in the ionosphere due to variations in $T_{e}, T_{i}$, or electron density are reflected in the polar wind, but there is a time delay because of the propagation time required for the disturbance to move from low to high altitudes.

2. Plasma convection through the auroral oval and high electric field regions produces transient $O^{+}$upflows and downflows. Typically, the $\mathrm{H}^{+}$upward flows are enhanced when the plasma convects into these regions and reduced when it convects out of them.

3. The density structure in the polar wind can be considerably more complicated than in the underlying ionosphere because of horizontal convection and changing vertical propagation speeds due to spatially varying ionospheric temperatures. For example, transient $\mathrm{H}^{+}$ downflows can occur at intermediate altitudes even though the $\mathrm{H}^{+}$flow is upward from the ionosphere and upward at high altitudes $(9000 \mathrm{~km})$.

4. During the storm, there is an overall increase in $T_{e}, T_{i}$, and the $\mathrm{O}^{+}$density in the $F$ region. The maximum $T_{e}$ and $T_{i}$ occur during the storm's main phase, but the maximum $\mathrm{O}^{+}$densities occur in the storm's recovery phase. This has a significant effect on the temporal variation of $\mathrm{H}^{+}$densities at high altitudes. 


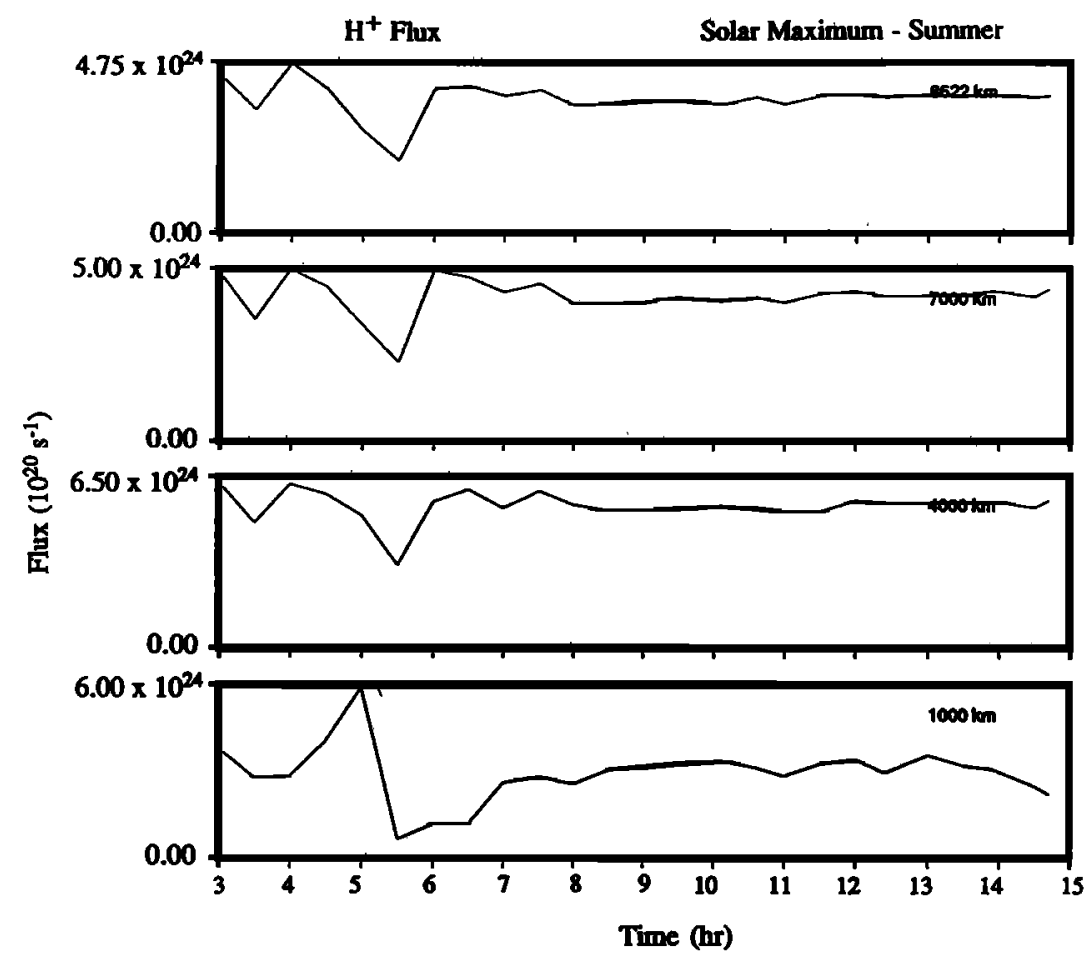

Figure 8. $\mathrm{H}^{+}$flow rate (ions $\mathrm{s}^{-1}$ ) as a function of time at selected altitudes. The flow rate is obtained by integrating the $\mathrm{H}^{+}$flux over the entire polar region at each altitude. The results are for summer solar maximum conditions.

5. During increasing magnetic activity, there is an overall increase in the polar wind outflow rate, but there is a time delay between the peak of the storm and the maximum $\mathrm{H}^{+}$outflow rate.

The comparison of the different seasonal and solar cycle cases yields the following general results:

1. For solar minimum winter conditions, both the $\mathbf{H}^{+}$and $\mathrm{O}^{+}$ velocities are typically upward in the polar region during enhanced magnetic activity. The ion drift velocities increase with altitude and at high altitudes both ions are supersonic. For $\mathrm{O}^{+}$, the maximum upward velocities are $300-500 \mathrm{~m} \mathrm{~s}^{-1}$ at $500 \mathrm{~km}$ and $3-5 \mathrm{~km} \mathrm{~s}^{-1}$ at $2500 \mathrm{~km}$, while for $\mathrm{H}^{+}$the maximum upward velocity is of the order of $20 \mathrm{~km} \mathrm{~s}^{-1}$ at $2500 \mathrm{~km}$. As the plasma convects out of the dayside storm oval and into the polar cap, large $\mathrm{O}^{+}$downflows can occur, with the downward $\mathrm{O}^{+}$velocity of the order of $7 \mathrm{~km} \mathrm{~s}^{-1}$ at $2500 \mathrm{~km}$.

During the peak of the storm (0500 to 0600 UT), there is a relative increase in the $\mathrm{O}^{+}$density throughout the polar region above about $1000 \mathrm{~km}$ (positive storm effect), and then there is a relative decrease in $\mathrm{n}\left(\mathrm{O}^{+}\right)$as the storm subsides ( $\mathrm{t}>6.5$ hours). However, at low altitudes $(500 \mathrm{~km})$, there is a general increase in $\mathrm{n}\left(\mathrm{O}^{+}\right)$from about 0500 to $0800 \mathrm{UT}$, so that the temporal variation of $\mathrm{n}\left(\mathrm{O}^{+}\right)$is "opposite" at high and low altitudes during the recovery phase of the storm. For $\mathrm{H}^{+}$, on the other hand, there is an " $\mathrm{H}^{+}$blowout" throughout the polar region at all altitudes shortly after the storm commences (negative storm effect), which is opposite to what occurs for $\mathrm{O}^{+}$. The net result is that $\mathrm{O}^{+}$is the dominant ion to altitudes as high as $9000 \mathrm{~km}$ throughout the bulk of the polar region during enhanced magnetic activity.

For $\mathrm{O}^{+}$, the integrated flow rate across a given altitude (ions $\mathrm{s}^{-1}$ ) is initially upward during storm commencement and then it is downward at most altitudes. At $8622 \mathrm{~km}$, the maximum upward $\mathrm{O}^{+}$flow rate occurs during the storm's main phase and is
$3 \times 10^{23}$ ions $\mathrm{s}^{-1}$. For $\mathrm{H}^{+}$, the integrated flow rate is upward at all altitudes and times. However, at $8622 \mathrm{~km}$, the maximum $\mathrm{H}^{+}$ flow rate occurs 1 hour after the storm's main phase and is about $1.7 \times 10^{25}$ ions $\mathrm{s}^{-1}$.

2. For solar maximum summer conditions, there is a large difference in the ionosphere-thermosphere conditions compared to those for solar minimum winter. At $500 \mathrm{~km}$, the atomic oxygen density is a factor of 11 higher, the $O^{+}$density is a factor of 22 higher, the atomic hydrogen density is a factor of 18 lower, and the $\mathrm{H}^{+}$density is about a factor of 10 lower. The higher $\mathrm{O}^{+}$densities yield much larger upward $\mathrm{O}^{+}$fluxes during the storm. At $800 \mathrm{~km}$, the upward $\mathrm{O}^{+}$flux is about $4 \times 10^{9} \mathrm{~cm}^{-2}$ $\mathrm{s}^{-1}$ at solar maximum summer and only about $2 \times 10^{8} \mathrm{~cm}^{-2} \mathrm{~s}^{-1}$ at solar minimum winter. Also, because the bulk of the polar region is sunlit in summer, the ion density distributions tend to be more uniform for solar maximum summer than for solar minimum winter.

During the peak of the storm, the $\mathrm{O}^{+}$temporal morphologies are opposite at high and low altitudes. The $\mathrm{O}^{+}$density increases at high altitudes (positive storm effect) and decreases at low altitudes (negative storm effect). The $\mathrm{O}^{+}$temporal morphologies are also opposite during the recovery phase, but they are reversed. For $\mathrm{H}^{+}$, the temporal morphologies at high and low altitudes are in phase with the $\mathrm{O}^{+}$morphologies. That is, during the storm's peak, $n\left(\mathrm{H}^{+}\right)$increases at high altitudes and decreases at low altitudes, and then the trend is reversed in the recovery phase. Note that these $\mathrm{H}^{+}$and $\mathrm{O}^{+}$temporal variations are different from what occurs at solar minimum winter. Another very important result is that during enhanced geomagnetic activity $\mathrm{O}^{+}$is the dominant ion up to $8000 \mathrm{~km}$ throughout the polar region at solar maximum summer.

The temporal variation of the integrated $\mathrm{O}^{+}$flow rate across a given altitude for solar maximum summer is qualitatively very 
similar to that for solar minimum winter, but that is not the case for $\mathrm{H}^{+}$. Quantitatively, the $\mathrm{O}^{+}$flow rates are larger (by about a factor of 10 at $8600 \mathrm{~km}$ ) and the $\mathrm{H}^{+}$flow rates are lower (by a factor of 3-5) for solar maximum summer than for solar minimum winter.

3. Considering all seasonal and solar cycle conditions, the following general result is obtained for the ion densities. For $\mathrm{O}^{+}$, the "stormtime" variations in summer and in winter are "qualitatively" similar at solar maximum and again at solar minimum, but they differ at solar maximum and minimum. For $\mathrm{H}^{+}$, the stormtime variations at solar minimum and maximum are qualitatively similar both in winter and in summer, but they differ in winter and summer.

\subsection{Polar Wind Environment}

Before comparing our results to measurements, it is useful to relate our simulations to the real world. First, it should be noted that the "storm" scenario we adopted is idealized and there are many different ways to model a storm. The adoption of different convection and precipitation patterns and a different temporal variation for the storm profile will yield different quantitative and, in some cases, qualitative results. Nevertheless, the parameters we selected are "reasonable" and, therefore the general features we obtained should be indicative of the behavior of the global polar wind.

In this regard it is useful to compare the present simulation for solar minimum winter with the one published by Schunk and Sojka [1989]. As noted in subsection 3.4, in our first study we used a symmetric two-cell convection pattern, a different auroral oval, and a linear storm profile with a higher $K \boldsymbol{p}$ at the storm's peak (i.e., $K p=8$ ). For $\mathrm{O}^{+}$there was an increase in the density at all altitudes throughout most of the polar region during the peak of the storm. During the storm's recovery phase, the $\mathrm{O}^{+}$ densities continued to increase at low $(500 \mathrm{~km})$ and mid $(2500$ $\mathrm{km}$ ) altitudes in most areas, but they basically decreased at high altitudes $(9000 \mathrm{~km})$. These features are in general qualitative agreement with the results presented in this paper, although there are quantitative differences and differences in the details. With regard to $\mathrm{H}^{+}$, during the storm's peak the $\mathrm{H}^{+}$density decreased at high altitudes $(9000 \mathrm{~km})$, but at middle and low altitudes $(500$ to $2500 \mathrm{~km})$ there were polar regions where it increased and other regions where it decreased. This behavior is in contrast to the results obtained in the present simulation where an $\mathrm{H}^{+}$"blowout" occurred shortly after storm commencement. Hence, as expected, the use of different convection and precipitation patterns can lead to some differences in the results. Nevertheless, in the real world the convection and precipitation patterns change continuously as the IMF and solar wind dynamic pressure change, and this must be kept in mind when comparing simulation results to measurements.

The global ionosphere-polar wind simulations presented here correspond to the behavior of the "classical" polar wind. However, the polar wind may be affected by other processes not included in the classical picture, as shown schematically in Figure 9. Specifically, in sunlit regions escaping photoelectrons may provide an additional ion acceleration at high altitudes ( $>7000 \mathrm{~km}$ ) as they drag the thermal ions with them. This prócess would act to increase the $\mathrm{O}^{+}$and $\mathrm{H}^{+}$drift velocities in the polar regions where they are upward [Lemaire, 1972b; Tam et al., 1995]. Cusp ion beams and conics that have

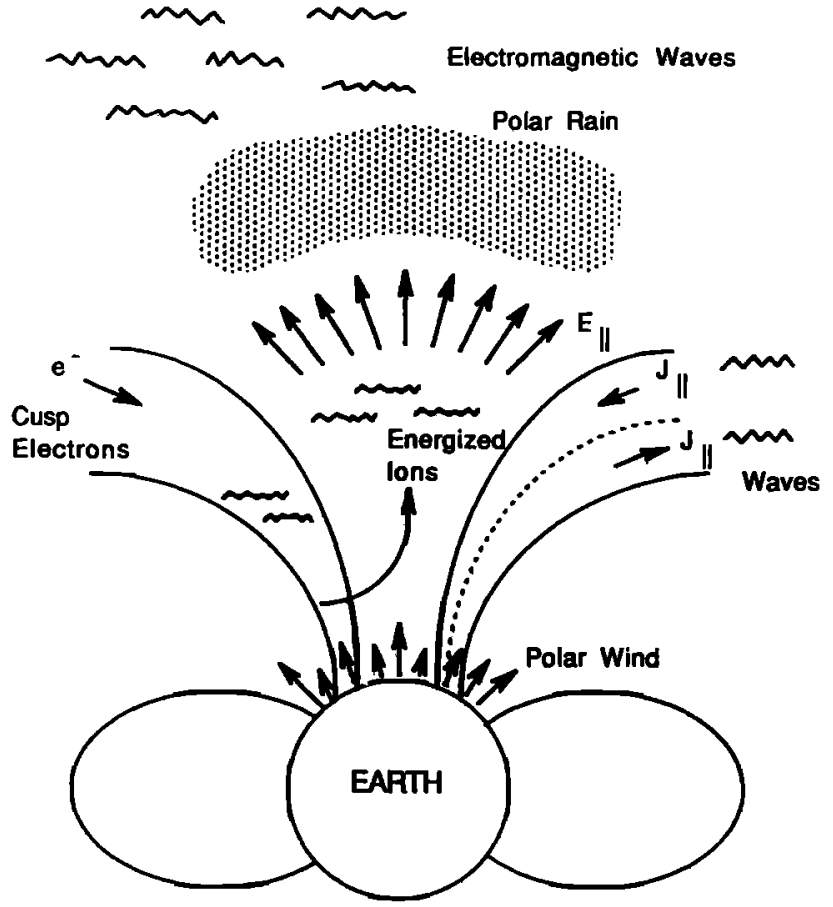

Figure 9. Schematic diagram showing nonclassical processes that may affect the polar wind.

convected into the polar cap can destabilize the polar wind when they pass through it at high altitudes. The resulting waveparticle interactions act to heat both $\mathrm{O}^{+}$and $\mathrm{H}^{+}$in a direction perpendicular to $B$, which then affects the escape velocities and fluxes [Barakat and Schunk, 1989; Chen and Ashour-Abdallah, 1990]. The interaction of hot magnetospheric electrons (polar rain, showers and squall) with the cold, upflowing, polar wind electrons can result in a double layer potential drop over the polar cap (at about $4000 \mathrm{~km}$ ), which can energize the $\mathrm{O}^{+}$and $\mathrm{H}^{+}$ ions. The $\mathrm{H}^{+}$energy gain varies from a few $\mathrm{eV}$ to about $2 \mathrm{keV}$ depending on the hot electron density and temperature [Barakat and Schunk, 1984a; Winningham and Gurgiolo, 1982]. At altitudes above $6000 \mathrm{~km}$ in the polar cap, electromagnetic turbulence can significantly affect the ion outflow via perpendicular heating though wave-particle interactions [Ludin et al., 1990; Barakat and Barghouthi, 1994]. Also, above about $3000 \mathrm{~km}$ in the polar cap, centrifugal acceleration will act to increase ion upward velocities, which may affect ion densities at high altitudes [Cladis, 1986; Swift, 1990; Horwitz et al., 1994; Demars et al., 1996]. Finally, anomalous resistivity on auroral field lines can affect the polar wind as the plasma convects through the nocturnal auroral oval [Ganguli and Palmadesso, 1987; Ganguli, 1993, 1994].

At this time, it is not possible to rigorously include all of the nonclassical processes discussed above, and it is difficult to guess what their ultimate effect is because the problem is highly nonlinear. Furthermore, except for the study by Ganguli [1993, 1994], when the various nonclassical processes were deduced to be important, the deductions were based on "one-dimensional" steady state or time-dependent simulations applied at a "fixed" location. Also, only the process being studied was typically included. However, when all of the processes are included and when the plasma is allowed to convect through the different 
regions of the high-latitude ionosphere in a realistic manner, the conclusion as to the importance of a given process may change.

\subsection{Comparison With Measurements}

It is not possible to conduct a detailed comparison of our results with specific measurements because we would need an extensive data base of simultaneous complementary measurements to validate both our adopted magnetospheric inputs (convection and precipitation patterns) and our global ion distributions. Nevertheless, some of the specific features, general trends, and ion parameter values we calculated can be compared, in a general way, with the extensive data base that is currently available. The data include both low-altitude (ionosphere) and high-altitude (polar wind) measurements from incoherent scatter radars and satellites. There are data pertaining to specific case studies and statistical studies, and we will focus only on the data most relevant to our simulations. However, it should be noted that if we had considered a larger storm or a storm with a longer duration, we would have obtained larger effects and vice versa.

Literally hundreds of global ionospheric simulations and model-data comparisons have been conducted that cover a wide range of seasonal, solar cycle, and geomagnetic activity conditions, and the simulations have successfully reproduced the observed trends and specific ionospheric features, such as the main trough, polar hole, tongue of ionization, and auroral enhancements [see, e.g., Schunk and Sojka, 1996; Sojka and Schunk, 1997, and references therein]. Therefore, with regard to the ionosphere, only "thermal ion upwelling" will be discussed since it directly affects the high-altitude polar wind.

Both satellite and incoherent scatter radar measurements have clearly established that enhanced upward flows of thermal ions are common in the cusp, noctumal oval, and polar cap [Lockwood et al., 1985; Yau et al., 1985a, b; Tsunoda et al., 1989; Yeh and Foster, 1990; Loranc et al., 1991; Wahlund et al., 1992; Blelly et al., 1996]. The ion upwelling events are characterized by enhanced ion and electron temperatures, enhanced upward $\mathrm{O}^{+}$velocities and fluxes, and elevated $\mathrm{O}^{+}$ densities at high altitudes. The transient events occur when the plasma convects into a region where ion and/or electron heating occurs, which causes the plasma to expand upwards. Subsequently, when the plasma convects out of the heated region, the plasma cools and a downflow occurs. However, not all of the plasma will return if there is a high-altitude energy source that is sufficiently strong to allow escape. On the dayside, the ion upwelling in the cleft and the subsequent downflow as the plasma convects into the polar cap is called the "cleft ion fountain" [Lockwood et al., 1985].

Tsunoda et al. [1989] studied thermal ion upwellings in the cusp/cleft region using Hilat satellite data taken at $800 \mathrm{~km}$. All of the ion upwellings observed were subsonic, with the upward $\mathrm{O}^{+}$velocity ranging from $300 \mathrm{~m} \mathrm{~s}^{-1}$ to $1.6 \mathrm{~km} \mathrm{~s}^{-1}$ and the $\mathrm{O}^{+}$flux varying from $2.4 \times 10^{8}$ to $6 \times 10^{9} \mathrm{~cm}^{-2} \mathrm{~s}^{-1}$. These events were spatially collocated with soft electron precipitation, upward field-aligned currents, and velocity gradients in the plasma convection. The maximum occurrence of ion upwellings was at the dayside convection throat in the cusp, where the ion and electron heating is a maximum. Loranc et al. [1991] conducted a statistical study of thermal ion upwellings using DE 2 satellite data taken at altitudes between 200 and $1000 \mathrm{~km}$. They found that for "southward IMF" the vertical ion flows were predominantly upward in the cusp and throughout the auroral zone and downward in the polar cap. Although upward $\mathrm{O}^{+}$speeds as large as $3 \mathrm{~km} \mathrm{~s}^{-1}$ could occur, $\mathrm{O}^{+}$vertical drifts between 100 range of from 250 to $1000 \mathrm{~m} \mathrm{~s}^{-1}$. Wahlund et al. [1992] used EISCAT radar data to study $\mathrm{O}^{+}$upflows in the topside ionosphere during auroral activity. They found that occasionally large $\mathrm{O}^{+}$ fluxes $\left(\sim 10^{10} \mathrm{~cm}^{-2} \mathrm{~s}^{-1}\right)$ and drift velocities $\left(\sim 1.5 \mathrm{~km} \mathrm{~s}^{-1}\right)$ could occur in the 900 to $1500 \mathrm{~km}$ altitude region. They identified two types of flow. Type 1 was characterized by enhanced electric fields, increased perpendicular ion temperatures, low electron densities below $300 \mathrm{~km}$, and little or no electron precipitation. The source of this outflow was determined to be ion-neutral frictional heating. Type 2 was characterized by enhanced electron temperatures, weak to moderate electric fields, and decreased or unaffected topside electron densities. This type of flow occurred above auroral arcs and was typically stronger than the type 1 flow. Finally, Keating et al. [1990] conducted a statistical study of large $\left.\bigodot 10^{9} \mathrm{~cm}^{-2} \mathrm{~s}^{-1}\right)$ transient, field-aligned ion flows using 3 years of incoherent scatter radar data. They correlated the flows observed at $400 \mathrm{~km}$ with $T_{e}, T_{i}$, and $\mathrm{N}_{e}$ in the lower ionosphere in an effort to identify the source of the upflows. They found that the number of upflowing events at $400 \mathrm{~km}$ depends on $T_{e}$ at lower altitudes. However, if $T_{i}$ and $T_{e}$ are both elevated, the magnitude of the upward ion flux increases. Electron density increases at lower altitudes were found to be of secondary importance with regard to generating upflows.

The measurements clearly indicate that transient ion upflows can be generated by enhanced $T_{e}, T_{i}$, and $\mathrm{N}_{e}$ at low altitudes. Also, previous one-dimensional simulations for a "fixed" geographical location have shown that substantial $O^{+}$upflows can be generated by "prescribing" transient electron heating [Whitteker, 1977], transient high-altitude ion heating [Gombosi et al., 1985], and transient low-altitude ion heating [Gombosi and Killeen, 1987; Loranc and St.-Maurice, 1994; Wilson, 1994].

However, the three-dimensional simulations presented in this and our previous paper [Schunk and Sojka, 1989] have shown that the magnitudes of the transient ion upflows and downflows depend on the background ionospheric and atmospheric conditions, the altitude of the electron and/or ion heating, and the length of time the convecting plasma stays in the heated region. When these features are modeled more rigorously, as we have done, the results obtained are consistent with the measurements. Specifically, we have found that (1) Most of the transient $\mathrm{O}^{+}$upflows are subsonic, (2) The upflows can be generated by $T_{e}, T_{i}$, and $\mathrm{N}_{e}$ enhancements, (3) For southward IMF, ion upflows typically occur in the cusp and throughout the auroral zone, and downflows occur in the polar cap. However, during increasing geomagnetic activity, ion upflows can occur in the polar cap as well, (4) The $O^{+}$vertical velocities typically are in the range of from 100 to $300 \mathrm{~m} \mathrm{~s}^{-1}$, (5) $T_{e}$ is the main driver of the large-scale ion upflow events, but the magnitudes of the upward $\mathrm{O}^{+}$fluxes and velocities are enhanced if $T_{i}$ is also elevated. This situation always occurs in the cusp at the location of the dayside convection throat (Figure 5a), (6) Upward $\mathrm{O}^{+}$fluxes of from $10^{7}$ to almost $10^{10} \mathrm{~cm}^{-2} \mathrm{~s}^{-1}$ can occur depending on both the local heating rate and the background geophysical conditions, (7) $\mathrm{O}^{+}$upflows occur within minutes in response to elevated $T_{e}$ and $T_{i}$. Electron and $250 \mathrm{~m} \mathrm{~s}^{-1}$ were observed more frequently than drifts in the 

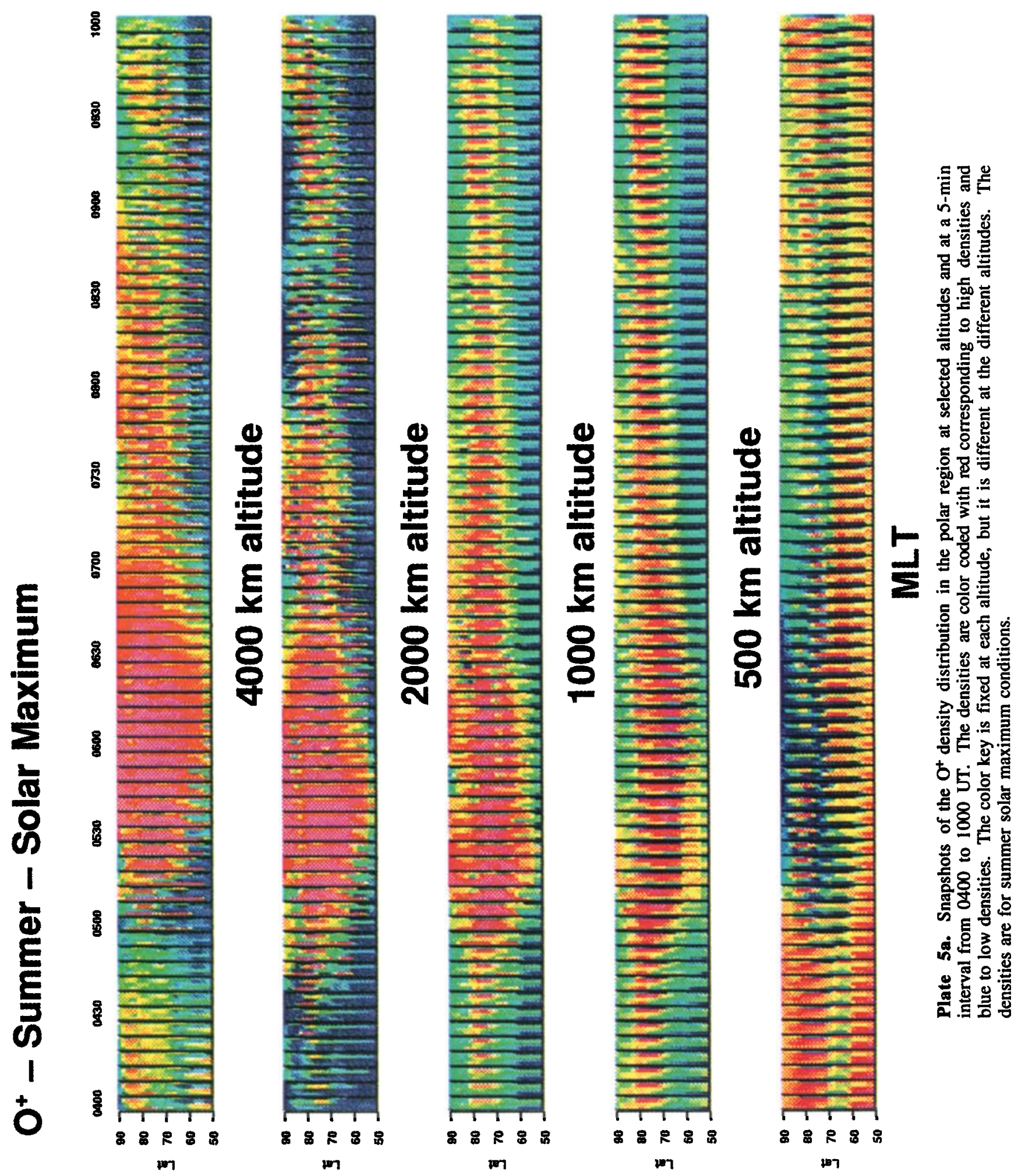

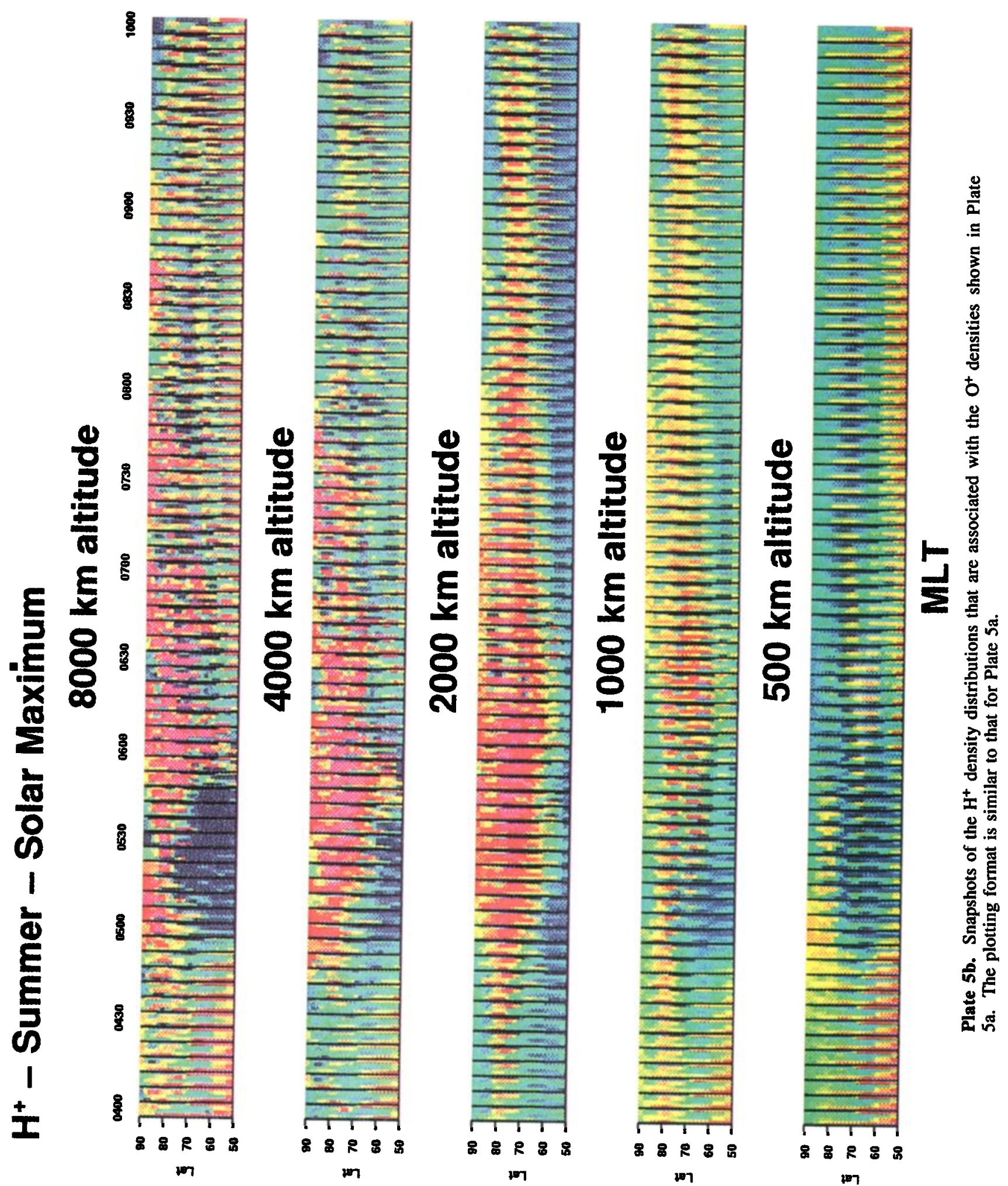
density enhancements also generate upflows, but there is a time delay of tens of minutes for them to be effective (not explicitly shown). It would be difficult for radars to observe such upflows because the plasma convects out of the radar field of view before the ion upflow becomes substantial. Note that all of these features are completely consistent with the available measurements.

To get stronger ion upflows, we merely need to select a convection pattern with stronger convection features, a precipitation pattern with more intense precipitation, a stronger storm, or a longer lasting storm. That is, it is necessary to get the correct magnetospheric inputs to model a specific event. In this regard, it should be noted that Blelley et al. [1996] successfully modeled an intermittent ion outflow event measured with the EISCAT radar [Blelly and Alcadyé, 1994]. Using estimates of the field-aligned currents and convection electric fields obtained from the radar measurements, they were able to model all of the features associated with the event, including an upward $\mathrm{O}^{+}$velocity of $600 \mathrm{~m} \mathrm{~s}^{-1}$ at $1000 \mathrm{~km}$, an elevated $T_{e}$ of $7000 \mathrm{~K}$ at $1000 \mathrm{~km}$, a $600 \mathrm{~K}$ increase in $T_{i}$, and a factor of 2 reduction in $\mathrm{N}_{\mathrm{e}}$ in the lower $F$ region.

Pollock et al. [1990] carefully analyzed DE 1 satellite data for 39 thermal ion upwelling events at "high altitudes" in the vicinity of the cleft. The events selected correspond to the strongest upward flow cases that were observed. For each event, the ion densities, drift velocities, and fluxes were determined from a range of instruments. The measurements covered altitudes from 2000 to $13,300 \mathrm{~km}$ during a "solar maximum" period (October 1981 to October 1983). Typical values for the $\mathrm{O}^{+}$density, upward velocity, and flux were $600 \mathrm{~cm}^{-3}, 3 \mathrm{~km} \mathrm{~s}^{-1}$, and $6 \times 10^{8} \mathrm{~cm}^{-2} \mathrm{~s}^{-1}$ (normalized to $1000 \mathrm{~km}$ ), but the ranges for the parameters were $\left(10^{2}-2 \times 10^{3} \mathrm{~cm}^{-3}\right),(1-7 \mathrm{~km} / \mathrm{s})$, and $(4 \times$ $10^{7}-5 \times 10^{9} \mathrm{~cm}^{-2} \mathrm{~s}^{-1}$ ). Typical values for the $\mathrm{H}^{+}$density, upward velocity, and flux were $50 \mathrm{~cm}^{-3}, 16 \mathrm{~km} / \mathrm{s}$, and $2 \times 10^{8}$ $\mathrm{cm}^{-2} \mathrm{~s}^{-1}$, with ranges being $\left(5-400 \mathrm{~cm}^{-3}\right),(6-30 \mathrm{~km} / \mathrm{s})$, and $(3 \times$ $\left.10^{7}-10^{9} \mathrm{~cm}^{-2} \mathrm{~s}^{-1}\right)$. Our simulation results for solar maximum are consistent with these measurements. For example, as the plasma following the trajectory in Figure 4 convects into the dayside oval during the storm, the ion upwelling event at about $5 \mathrm{hr}$ UT is characterized by peak values, at $2500 \mathrm{~km}$, of $\mathbf{n}\left(\mathrm{O}^{+}\right) \sim$ $2 \times 10^{3} \mathrm{~cm}^{-3}, \mathrm{U}\left(\mathrm{O}^{+}\right) \sim 2 \mathrm{~km} \mathrm{~s}^{-1}, \mathrm{~F}\left(\mathrm{O}^{+}\right) \sim 6 \times 10^{8} \mathrm{~cm}^{-2} \mathrm{~s}^{-1}, \mathrm{n}\left(\mathrm{H}^{+}\right) \sim$ $30 \mathrm{~cm}^{-3}, \mathrm{U}\left(\mathrm{H}^{+}\right) \sim 7 \mathrm{~km} \mathrm{~s}^{-1}$, and $\mathrm{F}\left(\mathrm{H}^{+}\right) \sim 4 \times 10^{7} \mathrm{~cm}^{-3}$ (Figure 7a). These values are within the ranges measured, and so are the calculated values for other trajectories.

Polar wind measurements have also been made at high altitudes in the polar cap. Chandler et al. [1991] conducted a statistical study using DE 1 data taken at latitudes greater than $70^{\circ} \Lambda$ and at altitudes between 1000 and $4000 \mathrm{~km}$. The data were for the 1981-1983 period, at which time there was moderate to active solar conditions. With regard to the field-aligned bulk velocities, they found that the "average" $\mathrm{H}^{+}$velocity was nearly constant below $2000 \mathrm{~km}$ and increased with altitude from about 3 to $4 \mathrm{~km} \mathrm{~s}^{-1}$ near $2000 \mathrm{~km}$ to about $10 \mathrm{~km} \mathrm{~s}^{-1}$ near $4000 \mathrm{~km}$. However, at a given altitude, there was a fairly large spread about the average $\mathrm{H}^{+}$velocity; it varied from about 0 to $8 \mathrm{~km} \mathrm{~s}^{-1}$ below $2000 \mathrm{~km}$ and from about 0 to $25 \mathrm{~km} \mathrm{~s}^{-1}$ above $2000 \mathrm{~km}$. Some of the $\mathrm{H}^{+}$flows were deduced to be subsonic. Over the altitude range considered (1000 to $4000 \mathrm{~km}), \mathrm{O}^{+}$was the dominant ion and its bulk velocity was typically less than $2 \mathrm{~km}$ $\mathrm{s}^{-1}$, but the flow could be either upward or downward. They also found that the asymptotic ion outflow speeds were "generally" greater in summer than in winter (by 25-70\%) and larger on the dayside than on the nightside.
In a subsequent study by Chandler [1995], the DE 1 data were binned with respect to the IMF, and it was found that for southward $B_{2}$ the $\mathrm{O}^{+}$upflows occurred primarily in the cusp and the auroral zone at all local times, while the $\mathrm{O}^{+}$downflows were primarily restricted to the polar cap. Estimates for the "average" $\mathrm{O}^{+}$fluxes were $4 \times 10^{25}$ ions $\mathrm{s}^{-1}$ for the upflows and 1 $\times 10^{25}$ ions $\mathrm{s}^{-1}$ for the downflows, but the magnitudes varied with magnetic activity.

Abe et al. [1993a, b] also presented field-aligned ion drift measurements in the polar cap. The velocities were measured by the Akebono satellite at altitudes from 2000 to $10,000 \mathrm{~km}$, at invariant latitudes greater than $80^{\circ}$, and for the 1990-1991 period (solar maximum). Their measurements were qualitatively consistent with those of Chandler et al. [1991]. Specifically, they found that at a given altitude the "average" $\mathrm{H}^{+}$outflow velocity increased linearly with $T_{e}$. They also found that the $\mathrm{H}^{+}$ velocity increased rapidly with altitude and often exhibited a significant variability in the 2000 to $4000 \mathrm{~km}$ altitude region. However, quantitatively, their measurements yielded lower "average" $\mathrm{H}^{+}$velocities than those measured by Chandler $\mathrm{et}$ al. [1991]. The Abe et al. [1993a, b] average $\mathrm{H}^{+}$velocities were 1, 6 , and $12 \mathrm{~km} \mathrm{~s}^{-1}$ at 2000,4000 , and $10,000 \mathrm{~km}$, respectively, but above $6000 \mathrm{~km}$ the deviation about the average values was about $5 \mathrm{~km} \mathrm{~s}^{-1}$. For $\mathrm{O}^{+}$, the "average" velocity was very small up to about $5000 \mathrm{~km}$, and then it increased from $1 \mathrm{~km} \mathrm{~s}^{-1}$ (at $6000 \mathrm{~km}$ ) to $4 \mathrm{~km} \mathrm{~s}^{-1}$ (at 10,000 km). Again, there was a significant scatter about these average $\mathrm{O}^{+}$velocities. Finally, as was found by Chandler et al. [1991], the measurements showed a day-night asymmetry, with generally higher upward $\mathrm{H}^{+}$and $\mathrm{O}^{+}$velocities on the dayside where $T_{e}$ and $T_{i}$ were elevated.

Our simulations are in general agreement with the above ion velocity measurements, particularly those of Chandler et al. [1991] and Chandler [1995]. Specifically, the features that are in good agreement with the data are as follows: (1) At high altitudes, our simulations indicate that $\mathrm{O}^{+}$upflows occur in the cusp and throughout the auroral zone at all local times, while $\mathrm{O}^{+}$ downflows primarily occur in the polar cap. This should result for all two-cell convection patterns which contain antisunward flow over the polar cap and return flow equatorward of the auroral oval. As the plasma convects into the cusp/auroral oval, the enhanced electron and ion temperatures cause an upflow, and when it convects out of this region the temperatures cool and a downflow occurs. However, during increasing magnetic activity, ion upflows can occur in the polar cap for brief periods of time, (2) Between 2000 to $4000 \mathrm{~km}$, the $\mathrm{H}^{+}$velocity typically displays its greatest increase with altitude and it exhibits a large variability in this altitude region, (3) The upward $\mathrm{H}^{+}$and $\mathrm{O}^{+}$velocities are directly proportional to $T_{e}$. As a consequence, the upward ion velocities are generally greater on the dayside than on the nightside, (4) In regions where $T_{e}$ is low, subsonic $\mathrm{H}^{+}$outflows can occur, in agreement with the measurements. At certain altitudes and times, an $\mathrm{H}^{+}$downflow can occur (not measured), (5) Quantitatively, our calculated $\mathrm{H}^{+}$ and $\mathrm{O}^{+}$velocities are in better agreement with Chandler et al. [1991] and Chandler [1995] than with Abe et al. [1993a, b], both with regard to average values and the scatter about the average values. For example, near $2000 \mathrm{~km}$ at solar maximum, the calculated $\mathrm{H}^{+}$velocity is typically between 2 and $5 \mathrm{~km} \mathrm{~s}^{-1}$, but it can vary from almost zero to $20 \mathrm{~km} \mathrm{~s}^{-1}$. At $4000 \mathrm{~km}$, the calculated $\mathrm{H}^{+}$velocity is typically between 10 and $15 \mathrm{~km} \mathrm{~s}^{-1}$, but it can approach $25 \mathrm{~km} \mathrm{~s}^{-1}$ at certain times and places. The calculated $\mathrm{O}^{+}$velocity can be either upward or downward and its 
magnitude is typically less than $2-3 \mathrm{~km} \mathrm{~s}^{-1}$, but it can be larger on occasion (see Figure $7 \mathrm{~b}$ ). These values are in excellent agreement with the Chandler measurements. However, it should be noted that at altitudes above about $6000 \mathrm{~km}$, larger ion velocities would probably be calculated if we were to include nonclassical polar wind processes, such as heating from waveparticle interactions and the direct effects of photoelectrons and hot magnetospheric electrons.

The measurements also indicate that there are seasonal and day-night asymmetries in the ion outflow speeds, with generally higher ion outflow speeds on the dayside and in summer [Chandler et al., 1991; Abe et al., 1993a, b]. These asymmetries are evident in our simulations and are simply a result of the elevated electron temperatures that occur in the sunlit hemisphere (dayside or summer polar cap), which result in greater densities and velocities at high altitudes [Barakat and Schunk, 1983; Barakat et al., 1987; Cannata and Gombosi, 1989]. Also, at high altitudes, escaping photoelectrons may provide an additional ion acceleration in the sunlit hemisphere [Lemaire, 1972b; Tam et al., 1995], but that effect is not included in our calculations.

With regard to ion density measurements in the polar wind, Chandler et al. [1991] presented altitude profiles of the "average" $\mathrm{H}^{+}$and $\mathrm{O}^{+}$densities in the polar cap $\left(20^{\circ} \Lambda\right)$ over the altitude range from 1000 to $4000 \mathrm{~km}$. The average profiles were based on DE 1 RIMS data taken during active solar conditions (1981-1983). The average $O^{+}$density varied from 3000 to $700 \mathrm{~cm}^{-3}$ as altitude varied from 1000 to $4000 \mathrm{~km}$, while the average $\mathrm{H}^{+}$density varied from 200 to $30 \mathrm{~cm}^{-3}$ over the same altitude range. Hence an average, $\mathrm{O}^{+}$was the dominant ion between 1000 and $4000 \mathrm{~km}$ during solar maximum. However, at a given altitude, the $\mathrm{O}^{+}$density variation about the average value was about a factor of 10 . For $\mathrm{H}^{+}$, the density variation about the average was a factor of 10 at low altitudes and a factor of 100 at high altitudes. The data also suggested that much of the variability in the polar cap densities and outflows is a result of short timescale $(\leqslant 1$ hour) phenomena.

These measurements are again in general agreement with our solar maximum calculations. Specifically, at altitudes between 1000 and $4000 \mathrm{~km}, \mathrm{O}^{+}$is typically the dominant ion in the polar cap during the storm for both summer and winter conditions. However, at a given time, the calculated $\mathrm{O}^{+}$density can vary markedly over the polar region and at a given location it can vary markedly with time. For solar maximum summer conditions, the calculated $\mathrm{O}^{+}$densities typically vary between $10^{4}-10^{5} \mathrm{~cm}^{-3}$ at $1000 \mathrm{~km}$ and $10-700 \mathrm{~cm}^{-3}$ at $4000 \mathrm{~km}$ during the storm. At solar maximum winter the calculated $\mathrm{O}^{+}$densities are lower than these values. The calculated $\mathrm{H}^{+}$densities typically vary between $100-1000 \mathrm{~cm}^{-3}$ at $1000 \mathrm{~km}$ and $5-30 \mathrm{~cm}^{-}$ 3 at $4000 \mathrm{~km}$ during the storm for solar maximum summer conditions. Although the agreement with the "statistical" database is not perfect, it is acceptable, particularly in view of the fact that different convection-precipitation patterns and a different storm scenario would yield different quantitative results. The only real disagreement occurs after the storm at altitudes above about $4000 \mathrm{~km}$, where the calculated $\mathrm{O}^{+}$ densities can be orders of magnitude lower than the "average" measured values. When this occurs, $\mathrm{H}^{+}$becomes the dominant ion at these altitudes and times.

Persoon et al. [1983] presented DE 1 measurements of the local electron density at high altitudes in the northern polar cap region. The electron densities were determined from the plasma wave instrument, and the data were obtained during a "solar maximum" period that included both equinox and winter conditions (September 1981 to February 1982). The data covered the altitude range from 6378 to $23,343 \mathrm{~km}\left(2-4.66 R_{E}\right)$. The electron densities, which were plotted in one figure as a function of radial distance, displayed a fairly wide scatter at a given distance. The scatter was anticipated because the electron density exhibited a large variation both on individual orbits as well as from orbit to orbit, and all the densities from different latitudes, local times, and magnetic activity levels were used in the data base.

At the altitude range relevant to our study (6378 to $9000 \mathrm{~km}$ ), the measured electron densities varied from about 10 to $90 \mathrm{~cm}^{-3}$. For our solar maximum winter simulation, the calculated electron densities at altitudes between 6300 and $9000 \mathrm{~km}$ vary both as a function of time and over the polar cap, with the range being from about 1 to $150 \mathrm{~cm}^{-3}$. The calculated values go beyond the measured range, but the agreement is not bad. The difference between the calculated and measured values may be due to the fact that we did not include high-altitude energization processes in our simulations.

A statistical study of the solar cycle and geomagnetic activity variations of "energetic" ion outflows was conducted by Yau et al. [1985a, 1988]. The data were obtained with the energetic ion composition spectrometer on DE 1 during 1981 1986, when $F_{10.7}$ varied from 70 to 250 . The instrument covered the energy range from $10 \mathrm{eV}$ to $17 \mathrm{keV}$, but $90 \%$ of the cases were for energies less than $1 \mathrm{keV}$. For each $F_{10.7}$ level, the ion outflow rates increased exponentially with $K p$. The $\mathrm{O}^{+}$ rate (ions $\mathrm{s}^{-1}$ ) increased by a factor of 20 and the $\mathrm{H}^{+}$rate (ions $s^{-1}$ ) increased by a factor of 4 as $K p$ varied from 0 to 6 . For high $K p$, the outflows were dominated by $\mathrm{O}^{+}$, while for low $K p, \mathrm{H}^{+}$ was the more prominent ion. At a given $K p$ value, the $\mathrm{O}^{+}$ outflow rate increased by a factor of 5 from solar minimum to solar maximum, while the $\mathrm{H}^{+}$outflow rate displayed a statistically insignificant variation ( $\leqslant$ factor of 2 ) with $F_{10.7}$.

Our "storm" simulations for the behavior of the "low-energy" polar wind ions are in qualitative agreement with the "statistical" behavior of the "energetic" outflowing ions. Specifically, our simulations indicate that at both solar maximum and minimum there is a large increase in the upward $\mathrm{O}^{+}$flux and a smaller increase in the upward $\mathrm{H}^{+}$flux as magnetic activity increases. For high $\mathrm{Kp}, \mathrm{O}^{+}$is the dominant upflowing ion, while for low $\mathrm{Kp} \mathrm{H}^{+}$dominates. Also, our simulations indicate that during the storm the upward $\mathrm{O}^{+}$flux is much larger at solar maximum than at solar minimum, while there is a much smaller change in the upward $\mathrm{H}^{+}$flux as solar activity changes. These features are in good qualitative agreement with the energetic ion measurements, but a quantitative comparison cannot be made because we did not include high-altitude energization processes in our simulations, and consequently, most of the upflowing $\mathrm{O}^{+}$ions return to the ionosphere when our storm subsides.

A statistical study of the solar cycle variation of the $F$ region ionosphere (200 to $1000 \mathrm{~km}$ ) was conducted by Grebowsky et al. [1990, 1993]. The measurements were relevant to summer conditions at noontime. The solar maximum $\left(F_{10.7} \approx 150\right)$ data were obtained from OGO satellite measurements, while the solar minimum $\left(F_{10.7} \approx 90\right)$ data were from the AE-C and D satellites. The measured densities and solar cycle variation were in remarkable agreement with the "1-dimensional", "steady state" polar wind calculations of Cannata and Gombosi [1989]. These authors modeled the solar cycle variation of the polar wind for quiet magnetic activity, summer conditions, at noon and for a 
location of $80^{\circ} \mathrm{N}$ latitude. They found that the upward $\mathrm{O}^{+}$flux increases by a factor of 10 and the upward $\mathrm{H}^{+}$flux increases by a factor of $2-3$ below $4000 \mathrm{~km}$ in going from solar minimum to maximum. They also found that the ion outflow is dominated by $\mathrm{O}^{+}$at solar maximum and by $\mathrm{H}^{+}$at solar minimum.

The Grebowsky et al. [1990, 1993] and Yau et al. [1985a, 1988] measurements are also in basic agreement with the onedimensional polar wind simulations of Barakat et al. [1987]. These authors applied a high-altitude energization source in order to calculate the "limiting" or "maximum" $\mathrm{H}^{+}$and $\mathrm{O}^{+}$escape fluxes that can occur for different solar cycle, seasonal, and geomagnetic activity conditions. For a fixed geographical location and steady state flows, the authors found that as solar activity increases the limiting $\mathrm{O}^{+}$escape flux increases and the limiting $\mathrm{H}^{+}$escape flux decreases. They also found that the $\mathrm{O}^{+}$ content of the ion outflow increases with increasing solar activity, with increasing geomagnetic activity, and with increasing solar elevation from winter to summer.

Except for the decrease in the limiting $\mathrm{H}^{+}$escape flux with increasing solar activity found by Barakat et al. [1987], the measurements of Grebowsky et al. [1990, 1993] and Yau et al. [1985a, 1988] are in general agreement with the onedimensional steady state simulations [Barakat et al., 1987; Cannata and Gombosi, 1989] and our three-dimensional storm simulations. However, as noted previously [Barakat and Schunk, 1983; Barakat et al., 1987; Cannata and Gombosi, 1989; Schunk and Sojka, 1989], the ion outflow that one calculates depends on the local ionospheric and atmospheric densities, temperatures, and winds. Hence vastly different ion outflows can occur at different locations at a specified time or at different times at the same location. This is clearly evident in our three-dimensional storm simulations and is the main reason why our results can only be compared in a general way to the measurements and previous one-dimensional modeling studies.

Acknowledgment. This research was supported by NASA grant NAG5-1484 and NSF grant ATM-93-08163 to Utah State University.

The Editor thanks J. M. Grebowsky and J. F. Lemaire for their assistance in evaluating this paper.

\section{References}

Abe, T., B. A. Whalen, A. W. Yau, R. E. Horita, S. Watanabe, and E. Sagawa, EXOS D (Akebono) suprathermal mass spectrometer observations of the polar wind, J. Geophys. Res., 98, 11191-11203, 1993a.

Abe, T., B. A. Whalen, A. W. Yau, S. Watanabe, E. Sagawa, and K. I. Oyama, Altitude profile of the polar wind velocity and its relationship to ionospheric conditions, Geophys. Res. Lett., 20, 2825-2828, $1993 \mathrm{~b}$.

Axford, W. I., The polar wind and the terrestrial helium budget, $J$. Geophys. Res., 73, 6855-6859, 1968.

Banks, P. M., and T. E. Holzer, The polar wind, J. Geophys. Res., 73, 6846-6854, 1968.

Banks, P. M., and T. E. Holzer, Features of plasma transport in the upper atmosphere, J. Geophys. Res., 74, 6304-6316, 1969.

Barakat, A. R., and I. A. Barghouthi, The effect of wave-particle interactions on the polar wind $\mathrm{O}^{+}$, Geophys. Res. Lett., $21,2279-2282$, 1994:

Barakat, A. R., and R. W. Schunk, $\mathrm{O}^{+}$ions in the polar wind, J. Geophys. Res., 88, 7887-7896, 1983.

Barakat, A. R., and R. W. Schunk, Effect of hot electrons on the polar wind, J. Geophys. Res., 89, 9771-9784, 1984a.

Barakat, A. R., and R. W. Schunk, $\mathrm{O}^{+}$charge exchange in the polar wind, J. Geophys. Res., 89, 9835-9839, 1984b.

Barakat, A. R., and R. W. Schunk, Stability of the polar wind, J. Geophys. Res., 92, 3409-3415, 1987.

Barakat, A. R., and R. W. Schunk, Stability of $\mathrm{H}^{+}$beams in the polar wind J. Geophys. Res., 94, 1487-1494, 1989.
Barakat, A. R., R. W. Schunk, T. E. Moore, and J. H. Waite, Ion escape fluxes from the terrestrial high-latitude ionosphere, J. Geophys. Res., 92, $12255-12266,1987$.

Barakat, A. R., R. W. Schunk, I. A. Barghouthi, and J. Lemaire, Monte Carlo study of the transition from collision-dominated to collisionless polar wind flow, SPI Conf. Proc. Reprint Ser., 10, 431-437, 1990.

Barghouthi, I. A., A. R. Barakat, and R. W. Schunk, Monte Carlo study of the transition region in the polar wind: An improved collision model, J. Geophys. Res., 98, 17583-17591, 1993.

Bauer, S. J., The structure of the topside ionosphere, in Electron Density Profiles in Jonosphere and Exosphere, edited by J. Frihagen, p. 387, North-Holland, New York, 1966.

Bergmann, R., I. Roth, and M. K. Hudson, Linear stability of the $\mathrm{H}^{+}-\mathrm{O}^{+}$ two-stream instability in a magnetized plasma, J. Geophys. Res., 93, 4005-4020, 1988.

Blelly, P.-L., and D. Alcayde, Electron heat flow in the auroral ionosphere inferred from EISCAT-VHF observations, J. Geophys. Res., 99, 13181-13188, 1994.

Blelly, P.-L., and R. W. Schunk, A comparative study of the timedependent standard, 8-, 13-, and 16-moment transport formulations for the polar wind, Ann. Geophys., 11, 443-469, 1993.

Blelly, P.-L., A. Robineau, and D. Alcaydé, Numerical modeling of intermittent ion outflow events above EISCAT, J. Atmos. Terr. Phys., 58. 273-285, 1996.

Boris, J. P. and D. L. Book, Solution of continuity equations by the method of flux-corrected transport, in Methods in Computational Physics, vol. 16, edited by B. Alder, S. Fernbach, and M. Rotenberg, p. 85, Academic, San Diego, Calif., 1976.

Cannata, R. W., and T. I. Gombosi, Modeling the solar cycle dependence of quiet-time ion upwelling at high geomagnetic latitudes, Geophys. Res. Lett., 16, 1141-1144, 1989.

Chandler, M. O., Observations of downward moving $\mathrm{O}^{+}$in the polar topside ionosphere, J. Geophys. Res., 100, 5795-5800, 1995.

Chandler, M. O., J. H. Waite Jr., and T. E. Moore, Observations of polar ion outflows, J. Geophys. Res., 96, 1421, 1991.

Chen, M. W., and M. Ashour-Abdallah, Heating of the polar wind due to ion beam instabilities, J. Geophys. Res., 95, 18949-18968, 1990.

Cladis, J. B., Parallel acceleration and transport of ions from polar ionosphere to plasma sheet, Geophys. Res. Lett., 13, 893-896, 1986.

Demars, H. G., and R. W. Schunk, Solutions to bi-Maxwellian transport equations for the polar wind, Planet. Space Sci., 37, 85-96, 1989.

Demars, H. G., and R. W. Schunk, Semikinetic and generalized transport models of the polar and solar winds, J. Geophys. Res., 97, 1581-1595, 1992.

Demars, H. G., A. R. Barakat, and R. W. Schunk, Effect of centrifugal acceleration on the polar wind, J. Geophys. Res., 101, 24565-24571, 1996.

Dessler, A. J., and F. C. Michel, Plasma in the geomagnetic tail, $J$. Geophys. Res., 71, 1421-1426, 1966.

Fuller-Rowell, T.-J., D. Rees, S. Quegan, R. J. Moffett, and G. J. Bailey, Simulations of the seasonal and universal time variations of the highlatitude thermosphere and ionosphere using a coupled, threedimensional, global model, Pure Appl. Geophys., 127, 189-217, 1988.

Ganguli, S. B., 3-D polar plasma outflow, Eos Trans. $A G U$. 74, (43), 455, 1993.

Ganguli, S. B., 3-D simulations of the polar wind, STEP SIMPO Newsl., 4, p. 17, Kyoto Univ., Uji, Kyoto, Japan, 1994.

Ganguli, S. B., The polar wind, Rev. Geophys., 34, 311-348, 1996.

Ganguli, S. B., and P. J. Palmadesso, Plasma transport in the auroral return current region, J. Geophys. Res., 92, 8673-8690, 1987.

Ganguli, S. B., and P. J. Palmadesso, Classical and anomalous transport processes in the auroral retum current region, in Modeling Magnetospheric Plasma, Geophys. Monogr. Ser., vol. 44, edited by T. E. Moore and J. H. Waite, pp. 171-176, AGU, Washington, D.C., 1988.

Ganguli, S. B., H. G. Mitchell Jr., and P. J. Palmadesso, Behavior of ionized plasma in the high latitude topside ionosphere: The polar wind, Planet. Space Sci., 35, 703-713, 1987.

Gombosi, T. I., and T. L. Killeen, Effects of thermospheric motions on the polar wind: A time-dependent numerical study, J. Geophys. Res., 92, 4725-4729, 1987.

Gombosi, T. I., and A. F. Nagy, Time-dependent modeling of fieldaligned current-generated ion transients in the polar wind, $J$. Geophys. Res., 94, 359-369, 1989.

Gombosi, T. I., and R. W. Schunk, A comparative study of plasma expansion events in the polar wind, Planet. Space Sci., 36, 753-764, 1988. 
Gombosi, T. I., T. E. Cravens, and A. F. Nagy, A time-dependent theoretical model of the polar wind: Preliminary results, Geophys. Res. Lett., 12, 167-170, 1985.

Grebowsky, J. M., W. R. Hoegy, and T. C. Chen, Solar maximumminimum extremes in the summer noontime polar cap $F$-region ion composition: The measurements, J. Geophys. Res., 95, 12269-12276, 1990.

Grebowsky, J. M., W. R. Hoegy, and T. C. Chen, High latitude fieldaligned light ion flows in the topside ionosphere deduced from ion composition and plasma temperatures, J. Atmos. Terr. Phys., 55, 1605$1617,1993$.

Gurgiolo, C., and J. L. Burch, Composition of the polar wind - not just $\mathrm{H}^{+}$ and $\mathrm{He}^{+}$, Geophys. Res. Lett., 12, 69-72, 1985.

Hardy, D. A., M. S. Gussenhoven, and E. Holeman, A statistical model of auroral electron precipitation, J. Geophys. Res., 90, 4229-4248, 1985.

Hedin, A. E., et al., A global thermospheric model based on mass spectrometer and incoherent scatter data, MSIS $1, \mathrm{~N}_{2}$ density and temperature, J. Geophys. Res., 82, 2139-2147, 1977.

Heelis, R. A., J. K. Lowell, and R. W. Spiro, A model of the high-latitude ionospheric convection pattern, J. Geophys. Res., 87, 6339-6345, 1982.

Heppner, J. P., High latitude electric fields and the modulations related to interplanetary magnetic field parameters, Radio Sci., 8, 933-948, 1973.

Heppner, J. P., and N. C. Maynard, Empirical high-latitude electric field models, J. Geophys. Res., 92, 4467-4489, 1987.

Ho, C. W., J. L. Horwitz, N. Singh, and G. R. Wilson, Plasma expansion and evolution of density perturbations in the polar wind: Comparison of semikinetic and transport models, J. Geophys. Res., 98, 1358113593, 1993.

Hoffman, J. H., and W. H. Dodson, Light ion concentrations and fluxes in the polar regions during magnetically quiet times, J. Geophys. Res. 85, 626-632, 1980.

Holzer, T. E., J. A. Fedder, and P. M. Banks, A comparison of kinetic and hydrodynamic models of an expanding ion-exosphere, $J$. Geophys. Res., 76, 2453-2468, 1971.

Horwitz, J. L., C. W. Ho, H. D. Scarbo, and G. R. Wilson, Centrifugal acceleration of the polar wind, J. Geophys. Res., 99, 15051-15064, 1994.

Keating, J. G., F. J. Mulligan, D. B. Doyle, K. J. Winser, and M Lockwood, A statistical study of large field-aligned flows of thermal ions at high-latitudes, Planet. Space Sci., 38, 1187-1201, 1990.

Kelly, M. C., The Earth's Ionosphere, Academic, San Diego, Calif., 1989.

Killeen, T. L., P. B. Hays, G. R. Carignan, R. A. Heelis, W. B. Hanson, N. W. Spencer, and L. H. Brace, lon-neutral coupling in the high-latitude $F$ region: Evaluation of ion heating terms from Dynamics Explorer 2, J. Geophys. Res., 89, 7495-7508, 1984.

Lemaire, $\mathrm{J}, \mathrm{O}^{+}, \mathrm{H}^{+}$, and $\mathrm{He}^{+}$ion distributions in a new polar wind model, J. Atmos. Terr. Phys., 34, 1647-1656, 1972a.

Lemaire, J., Effect of escaping photoelectrons in a polar exospheric model, Space Res., 12, 1413-1416, 1972b.

Lemaire, J., and M. Scherer, Model of the polar ion-exosphere, Planet. Space Sci., 18, 103-120, 1970.

Lemaire, J., and M. Scherer, Kinetic models of the solar and polar winds, Rev. Geophys., 11, 427, 1973

Lemaire, J., and M. Scherer, Field aligned distribution of plasma mantle and ionospheric plasmas, J. Atmos. Terr. Phys., 40, 337-342, 1978.

Li, P., G. R. Wilson, and J. L. Horwitz, Effect of mid-altitude ion heating on ion outflow at polar latitudes, J. Geophys. Res., 93, 9753-9764, 1988.

Lockwood, M., M. O. Chandler, J. L. Horwitz, J. H. Waite Jr., T. E. Moore, and C. R. Chappell, The cleft ion fountain, J. Geophys. Res., 90, 9736, 1985

Loranc, M., and J.-P. St.-Maurice, A time-dependent gyro-kinetic model of thermal ion upflows in the high-latitude $F$ region, $J$. Geophys. Res., 99, 17429-17451, 1994.

Loranc, M., W. B. Hanson, R. A. Heelis, and J.-P. St.-Maurice, A morphological study of vertical ionospheric flows in the high-latitude $F$ region, J. Geophys. Res., 96, 3627-3646, 1991.

Ludin, R., G. Gustafsson, A. I. Eriksson, and G. Marklund, On the importance of high-altitude low-frequency electric fluctuations for the escape of ionospheric ions, J. Geophys. Res., 95, 5905-5919, 1990.

Meriwether, J. W., T. L. Killeen, F. G. McCormac, A. G. Bums, and R. G. Roble, Thermospheric winds in the geomagnetic polar cap for solar minimum conditions, J. Geophys. Res., 93, 7478-7492, 1988.
Mitchell, H. G., and P. J. Palmadesso, A dynamic model for the auroral field line plasma in the presence of field-aligned current, $J$, Geophys. Res., 88, 2131-2139, 1983.

Moore, T. E., Modulations of terrestrial escape flux composition (by lowaltitude acceleration and charge exchange chemistry), $J$. Geophys. Res., 85, 2011-2016, 1980.

Nagai, T., J. H. Waite, J. L. Green, C. R. Chappell, R. C. Olsen, and R. H. Comfort, First measurements of supersonic polar wind in the polar magnetosphere, Geophys. Res. Lett., 11, 669-672, 1984.

Palmadesso, P. J., S. B. Ganguli, and H. G. Mitchell, Multimoment fluid simulations of transport processes in the auroral zones, in Modeling Magnetospheric Plasma, Geophys. Monogr. Ser., vol. 44, edited by T. M. Moore and J. H. Waite, pp. 133-143, AGU, Washington, D.C., 1988.

Persoon, A. M., D. A. Gumett, and S. D. Shawhan, Polar cap electron densities from DE 1 plasma wave observations, J. Geophys. Res., 88 10,123-10,136, 1983.

Pollock, C. J., M. O. Chandler, T. E. Moore, J. H. Waite Jr., C. R. Chappell, and D. A. Gurnett, A survey of upwelling ion events characteristics, J. Geophys. Res., 95, 18969, 1990.

Prölss, G. W., S. Werner, M. V. Codrescu, and A. G. Burns, The thermosphere-ionosphere storm of Dec. 8, 1982: Model predictions and observations, Adv. Space Res., in press, 1997.

Raitt, W. J., R. W. Schunk, and P. M. Banks, A comparison of the temperature and density structure in the high and low speed thermal proton flows, Planet. Space Sci., 23, 1103-1118, 1975.

Raitt, W. J., R. W. Schunk, and P. M. Banks, The influence of convection electric fields on thermal proton outflow from the ionosphere, Planet. Space Sci., 25, 291-302, 1977.

Roble, R. G., and E. C. Ridley, A thermosphere-ionosphere-mesosphereelectrodynamics general circulation model (time-GCM): Equinox solar cycle minimum simulations (30-500 km), Geophys. Res. Lett., 21 , 417-420, 1994.

Schunk, R. W., A mathematical model of the middle and high latitude ionosphere, Pure Appl. Geophys., 127, 255-303, 1988a.

Schunk, R. W., Polar wind tutorial, SPI Conf. Proc. Reprint Ser., 8, 81 $134,1988 b$

Schunk, R. W., and W. J. Raitt, Atomic nitrogen and oxygen ions in the daytime high-latitude $F$-region, J. Geophys. Res., 85, 1255-1272, 1980.

Schunk, R. W., and J. J. Sojka, A three-dimensional time-dependent model of the polar wind, J. Geophys. Res., 94, 8973-8991, 1989.

Schunk, R. W., and J. J. Sojka, Jonosphere-thermosphere space weather issues, J. Atmos. Terr. Phys., 58, 1527-1574, 1996.

Schunk, R. W., and D. S. Watkins, Electron temperature anisotropy in the polar wind, J. Geophys. Res., 86, 91-102, 1981.

Schunk, R. W., and D. S. Watkins, Proton temperature anisotropy in the polar wind, J. Geophys. Res., 87, 171-180, 1982.

Schunk, R. W., W. J. Raitt, and P. M. Banks, Effect of electric fields on the daytime high-latitude $E$ - and $F$-regions, J. Geophys. Res., 80, 3121-3130, 1975.

Schunk, R. W., W. J. Raitt, and A. F. Nagy, Effect of diffusion-thermal processes on the high-latitude topside ionosphere, Planet. Space Sci. 26, 189-191, 1978 .

Schunk, R. W., J. J. Sojka, and M. D. Bowline, Theoretical study of the electron temperature in the high latitude ionosphere for solar maximum and winter conditions, J. Geophys. Res., 91, 12041-12054, 1986

Singh, N., and R. W. Schunk, Temporal evolution of density perturbations in the polar wind, J. Geophys. Res., 90, 6487-6496, 1985.

Sojka, J. J., Global scale, physical models of the $F$ region ionosphere, $R e v$ Geophys., 27, 371-403, 1989.

Sojka, J. J., and R. W. Schunk, A theoretical study of the global $F$ region for June solstice, solar maximum, and low magnetic activity, $J$. Geophys. Res., 90, 5285-5298, 1985.

Sojka, J. J., and R. W. Schunk, Simulations of high latitude ionospheric climatology, J. Atmos. Terr. Phys., 59, 207-229, 1997.

Sojka, J. J., W. J. Raitt, and R. W. Schunk, A theoretical study of the highlatitude winter $F$-region at solar minimum for low magnetic activity, $J$. Geophys. Res., 86, 609-621, 1981.

Spiro, R. W., P. H. Reiff, and L. J. Maher, Precipitating electron energy flux and auroral zone conductances: An empirical model, $J$. Geophys. Res., 87, 8215-8227, 1982.

St.-Maurice, J.-P., and R. W. Schunk, Ion velocity distributions in the high latitude ionosphere, Rev. Geophys., 17, 99-134, 1979. 
Swift, D., Simulation of the ejection of plasma from the polar ionosphere, J. Geophys. Res., 95, 12103-12118, 1990.

Tam, S. W. Y., F. Yasseen, T. Chang, and S. B. Ganguli, Self-consistent photoelectron effects on the polar wind, Geophys. Res. Lett., 22, 2107-2110, 1995.

Tsunoda, R. T., R. C. Livingston, J. F. Vickrey, R. A. Heelis, W. B. Hanson, F. J. Rich, and P. F. Bythrow, Dayside observations of thermal-ion upwellings at $800 \mathrm{~km}$ altitude: An ionospheric signature of the cleft ion fountain, J. Geophys. Res.. 94, 15277-15290, 1989.

Wahlund, J.-E., H. J. Opgenoorth, I. Häggström, K. J. Winser, and G. $O$. L. Jones, EISCAT observations of topside ionospheric ion outflows during auroral activity: Revisited, J. Geophys. Res., 97, 3019-3037, 1992.

Walker, J. C. G., and M. H. Rees, lonospheric electron densities and temperatures in aurora, Planet. Space Sci., 16, 459, 1968.

Whitteker, J. H., The transient response of the topside ionosphere to precipitation, Planet. Space Sci., 25, 773, 1977.

Wilson, G. R., Semikinetic modeling of the outflow of ionospheric plasma through the topside collisional to collisionless transition region, $J$. Geophys. Res., 97, 10551-10565, 1992.

Wilson, G. R., Kinetic modeling of $\mathrm{O}^{+}$upflows resulting from $\mathbf{E} \times \mathbf{B}$ convection heating in the high-latitude $F$ region ionosphere, $J$. Geophys. Res., 99, 17453-17466, 1994.

Wilson, G. R., C. W. Ho, J. L. Horwitz, N. Singh, and T. E. Moore, A new kinetic model for time-dependent polar plasma outflow: lnitial results, Geophys. Res. Lett., 17, 263-266, 1990.

Winningham, J. D., and C. Gurgiolo, DE-2 photoelectron measurements consistent with a large scale parallel electric field over the polar cap, Geophys. Res. Lett., 9, 977, 1982.

Yasseen, F., J. M. Retterer, T. Chang, and J. D. Winningham, MonteCarto modeling of polar wind photoelectron distributions with anomalous heat flux, Geophys. Res. Lett. I6, 1023-1026, 1989.

Yau, A. W., P. H. Beckwith, W. K. Peterson, and E. G. Shelley, Longterm (solar-cycle) and seasonal variations of upflowing ionospheric ion events at DE-1 altitudes, J. Geophys. Res., 90, 6395, 1985a.

Yau, A. W, E. G. Shelley, W. K. Peterson, and L. Lenchyshyn, Energetic auroral and polar ion outflow at DE-1 altitudes: Magnitude, composition, magnetic activity dependence and long-term variations, J. Geophys. Res., 90, 8417, 1985 b.

Yau, A. W., W. K. Petersen, and E. G. Shelly, Quantitative parameterization of energetic ionospheric ion outflow, in Modeling Magnetospheric Plasma, Geophys. Monogr. Ser., vol. 44, edited by T. E. Moore and J. H. Waite, pp. 211-217, AGU, Washington, D. C., 1988.

Yeh, H.-C., and J. C. Foster, Storm time heavy ion outflow at mid-latitude, J. Geophys. Res., 95, 7881, 1990.

R. W. Schunk and J. J. Sojka, Center for Atmospheric and Space Sciences, Utah State University, SER Building Room 246, Logan, UT 84322-4405. (e-mail: schunk@cc.usu.edu; fasojka@sojka.cass.usu.edu)

(Received November 6, 1996; revised January 27, 1997; accepted January 28, 1997.) 